\title{
Characterization of laboratory simulated road paving-like asphalt by high performance liquid chromatography and gas chromatography-mass spectrometry
}

\author{
Brandon F. Law \\ West Virginia University
}

Follow this and additional works at: https://researchrepository.wvu.edu/etd

\footnotetext{
Recommended Citation

Law, Brandon F., "Characterization of laboratory simulated road paving-like asphalt by high performance liquid chromatography and gas chromatography-mass spectrometry" (2006). Graduate Theses, Dissertations, and Problem Reports. 1735.

https://researchrepository.wvu.edu/etd/1735

This Thesis is protected by copyright and/or related rights. It has been brought to you by the The Research Repository @ WVU with permission from the rights-holder(s). You are free to use this Thesis in any way that is permitted by the copyright and related rights legislation that applies to your use. For other uses you must obtain permission from the rights-holder(s) directly, unless additional rights are indicated by a Creative Commons license in the record and/ or on the work itself. This Thesis has been accepted for inclusion in WVU Graduate Theses, Dissertations, and Problem Reports collection by an authorized administrator of The Research Repository @ WVU. For more information, please contact researchrepository@mail.wvu.edu.
} 


\title{
Characterization of Laboratory Simulated Road Paving-Like Asphalt by High Performance Liquid Chromatography and Gas Chromatography-Mass Spectrometry
}

\author{
Brandon F. Law \\ Thesis submitted to the \\ College of Engineering and Mineral Resources \\ at West Virginia University \\ in partial fulfillment of the requirements \\ for the degree of \\ Master of Science \\ in \\ Industrial Hygiene \\ Warren Myers, Ph.D., Chair \\ Steven E. Guffey, Ph.D. \\ Paul D. Siegel, Ph.D.
}

Department of Industrial and Management Systems Engineering Morgantown, West Virginia

2006

Keywords: Asphalt, Bitumen, Sampling, Hygiene, GC/MS 


\section{Abstract}

\section{"Characterization of Laboratory Simulated Road Paving-Like Asphalt by High Performance Liquid Chromatography and Gas Chromatography-Mass Spectrometry"}

Prolonged, extensive exposure to asphalt fume has been associated with several adverse health effects. Inhaled polycyclic aromatic hydrocarbons (PAHs) from asphalt fume exposure are of concern. The objective of this study was to characterize both qualitative and quantitative differences between fumes generated at $150{ }^{\circ} \mathrm{C}$ and $180{ }^{\circ} \mathrm{C}$ using a well controlled laboratory road paving fume generation system. Fumes were characterized by (1) total vapor and particulate concentration, (2) simulated boiling point profile and (3) specific PAH content. The mean concentrations of the vapor fractions generated at $180{ }^{\circ} \mathrm{C}$ and $150{ }^{\circ} \mathrm{C}$ were $23.3 \mathrm{mg} / \mathrm{m}^{3}$ and $11.2 \mathrm{mg} / \mathrm{m}^{3}$, respectively, demonstrating a statistically significant increase in concentration with increasing asphalt temperature. The mean concentrations of the particulate fractions generated at $180{ }^{\circ} \mathrm{C}$ and $150{ }^{\circ} \mathrm{C}$ were $42.4 \mathrm{mg} / \mathrm{m}^{3}$ and $28.0 \mathrm{mg} / \mathrm{m}^{3}$, respectively. The simulated boiling point profile did not show a significant qualitative difference between the fumes generated at the two temperatures. Naphthalene, acenaphthene, fluorene, phenanthrene, fluoranthene, pyrene, and chrysene were identified and quantified from the fumes. 


\section{Acknowledgments}

I would like to give thanks to everyone at NIOSH who shared his or her expertise and equipment for this project. I would also like to thank Dr. Paul D. Siegel for helping me refine my skills in the science of chemical separation and identification, as well as refinement of basic scientific methods and record keeping. This research was funded in part, by an interagency agreement with NIOSH and NIEHS/NTP, interagency agreement Y1-ES-9045-01.

Of course, I owe a thank you to my friends and family. I owe a thanks to my parents George and Carol for always encouraging me. I owe a big thank you to my wife Diedre and our forthcoming child (this will be your first bedtime story). If it were not for the two of you I might have given up on improving myself and taken the easier road. 


\section{Table of Contents}

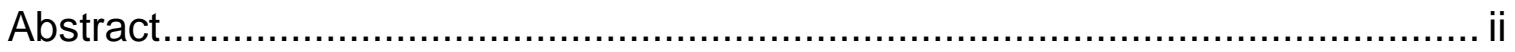

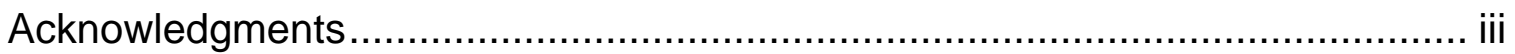

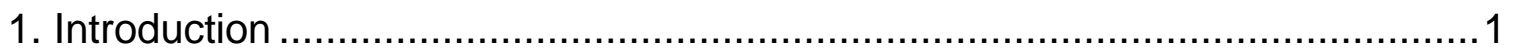

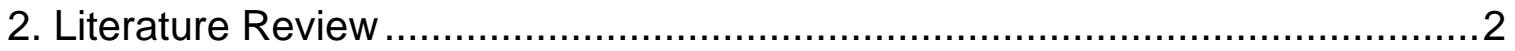

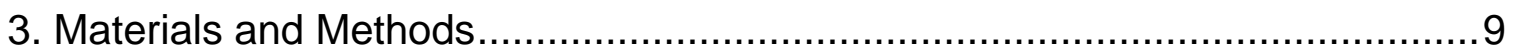

3.1 Asphalt Fume Generation, Sample Collection, and Extraction .....................9

3.2 Purification Methods Development ......................................................11

3.3 High Performance Liquid Chromatographic Fractionation for PAHs. ............12

3.4 Gas Chromatography and Mass Spectrometry Procedures........................ 13

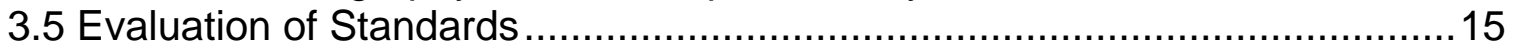

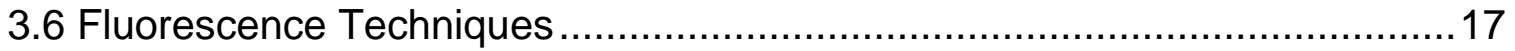

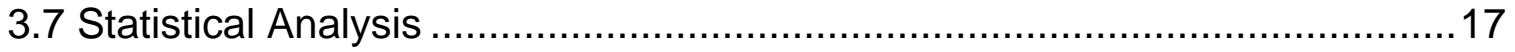

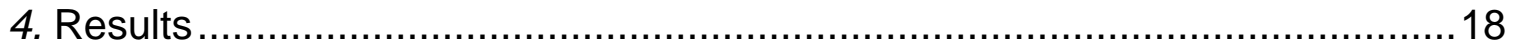

4.1 Standards Comparison and Response Factors .....................................18

4.2 Total, Vapor, and Particulate Asphalt Fume Chamber Concentrations.........25

4.3 Simulated Boiling Point Comparison ...................................................26

4.4 Identification of PAH Compounds in Asphalt Fume Condensate ..................30

4.5 Use of Fluorescent Techniques for the Identification and Quantification of

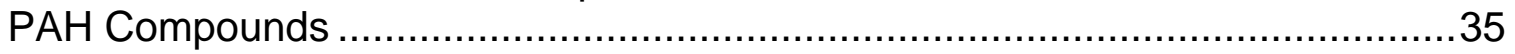

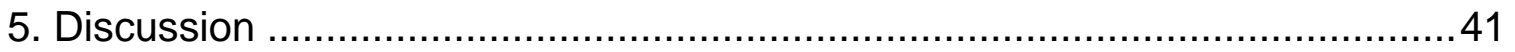

Appendix I. Standard Curves Used for Quantification of Filter

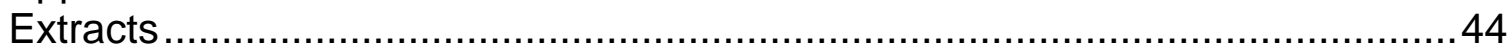

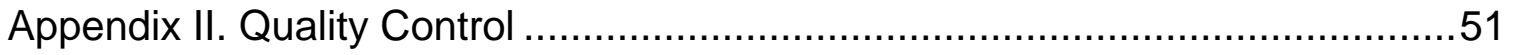

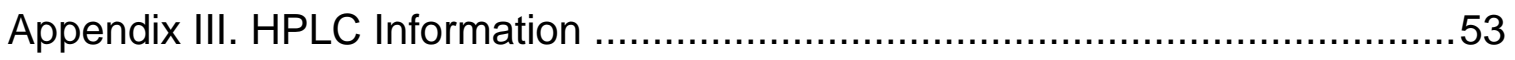

Appendix IV. Gas Chromatograph and Mass Spectrometer (GC/MS) Information

Appendix V. Sixteen PAH Compounds Included in the QTM Cocktail ................55 


\section{List of Figures}

Figure 1- benzo(a)pyrene gets metabolicly converted to mutagenic BPDE through several metabolic steps.

Figure 2- $1 \mathrm{~A}$ simplified illustration of the metabolism of $\mathrm{B}[\mathrm{a}] \mathrm{P}$. Copyright $@ 2002$ American Association for Cancer Research ${ }^{(22)}$.

Figure 3- A diagram of the simulated paving asphalt fume generator system. ...10

Figure 4- Diagram of the generation, collection, and analysis of the asphalt fume.

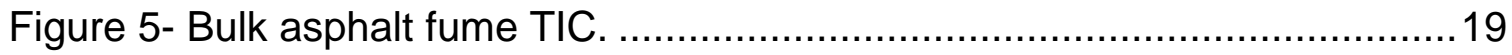

Figure 6- Reference standard kerosene TIC............................................20

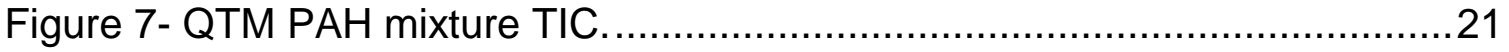

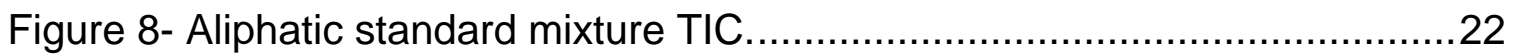

Figure 9- Bulk Asphalt GC/MS Standard Curve .........................................23

Figure 10- PAH Cocktail GC/MS Standard Curve ...........................................23

Figure 11- Reference Kerosene GC/MS Standard Curve ..............................24

Figure 12- Aliphatic Mixture $\left(\mathrm{C}_{8}-\mathrm{C}_{36}\right)$ Standard Curve.................................24

Figure 13- Exposure chamber air concentration of total asphalt fume and the particulate and vapor phases. Samples were collected on HEPA filters and XAD samplers, extracted into DCM and assayed by GCMS-TIC mode, $\mathrm{n}=4$.

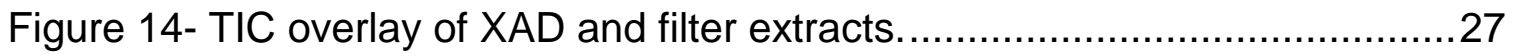

Figure $15-180{ }^{\circ} \mathrm{C}$ and $150^{\circ} \mathrm{C}$ filter (particulates) extracts overlaid. This shows a

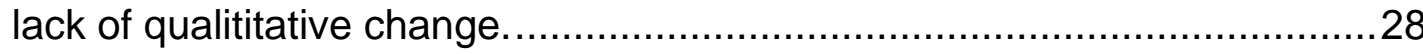

Figure $16-180^{\circ} \mathrm{C}$ and $150^{\circ} \mathrm{C}$ XAD (vapor) extracts overlaid. This shows a lack

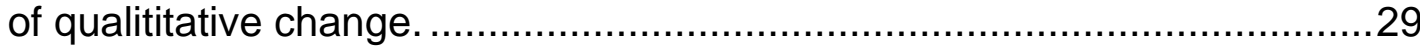

Figure 17- Simulated boiling point profile of $180{ }^{\circ} \mathrm{C}$ and $150{ }^{\circ} \mathrm{C}$ vapor and particulate fractions. 
Figure 18- Representative total ion chromatogram of the same fume sample before and after the preparatory HPLC cleanup procedure to remove aliphatics.

Figure 19- Representative EI-MS spectra are at 29.4 minutes. The top spectrum is the crude extract prior to HPLC cleanup, the bottom spectra is the same fume extract after the cleanup procedure. $178 \mathrm{~m} / \mathrm{z}$ is the molecular ion for

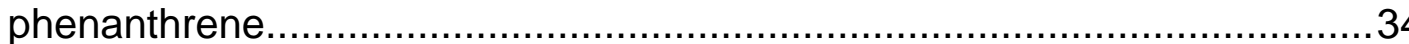




\section{List of Tables}

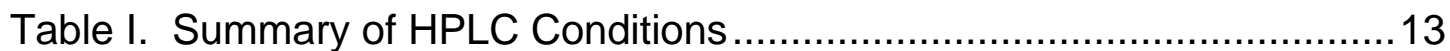

Table II. Ions Monitored by GC/MS Analysis, SIM Mode............................14

Table III. Summary of Gas Chromatogrpahy and Mass Spectrometry Conditions....

Table IV. Summary of identified compounds and their concentrations at the $150{ }^{\circ} \mathrm{C}$ and $180^{\circ} \mathrm{C}$...... 35 


\section{Introduction}

It is estimated that in the United States 300,000 workers are employed in the asphalt paving industry ${ }^{(1)}$. Several million tons of asphalt are used each year by the paving and roofing industries ${ }^{(2)}$. The potential for occupational exposure to road paving asphalt fumes is quite high. However, the health risk to workers is not known. The major route of exposure to asphalt fumes is by inhalation. Low levels of total polycyclic aromatic hydrocarbons (PAHs) present in asphalt fume have been detected through environmental and personal sampling during road paving operations. Enhanced levels of urinary 1-hydroxypyrene, a metabolite of PAHs, have been measured in road pavers ${ }^{(3)}$ and roofers ${ }^{(4)}$.

Asphalt fumes are complex and variable mixtures of inorganic particulate (derived from mineral aggregates) and organic compounds that include aliphatics, PAHs, and heteroatomic compounds containing sulfur, nitrogen, and oxygen ${ }^{(5)}$. The objective of this study is to characterize both qualitative and quantitative differences between fumes generated at $150{ }^{\circ} \mathrm{C}$ and $180^{\circ} \mathrm{C}$ using a well-controlled laboratory road-paving fume-generation system. Fumes were characterized by (1) total vapor and particulate concentration, (2) simulated boiling point profile, and (3) specific PAH content. 


\section{Literature Review}

Asphalt is a complex mixture of aliphatic and aromatic hydrocarbons obtained during the crude oil refinement process ${ }^{(5)}$. Asphalt is defined by the American Society for Testing and Materials (ASTM) ${ }^{(6)}$ as a dark brown to black cementitious material in which the predominating constituents are bitumens that occur in nature or are obtained in petroleum processing. There are some naturally occurring asphalts including native asphalt used in ancient construction ${ }^{(7)}$. Lake asphalt is another naturally occurring product, first used in the United States for paving in $1874^{(8)}$. Rock asphalt deposits contain from 5-25\% asphalt and exist as "soft flux" to "hard penetration" "(9). Rock asphalt is ground, sized, placed, and rolled to form pavement surfaces. Rock asphalts are found in Texas, Alabama, Oklahoma, Colorado, California, and Kentucky. Asphalt is also produced by processing petroleum crude oils and its composition can vary depending on the source of the crude oil, refinery processes, additives, and the application practices ${ }^{(10)}$. It is principally used for road paving $(\sim 87 \%)$ and roofing $(\sim 11 \%)$ in the United States ${ }^{(1)}$. It is known that asphalt contains polycyclic aromatic hydrocarbons (PAHs). However, the fumes that are a by product of road paving applications have not been well characterized and continue to pose analytical problems ${ }^{(11)}$. These problems are due to the complexity of the mixture, the lack of separation, and the lack of specificity in the assays used.

Problems with asphalt characterization are three-fold: (1) the variations in asphalt manufacturing, (2) the variations in feed stock crude oil, and (3) the variations within a single lot of asphalt. Manufactured asphalts derive their characteristics from the nature of the crude origins and by manufacturing process. There are refineries whose prime function is to produce asphalt, but asphalt is principally a product of integrated refineries. These refineries may select crude for a variety of other product requirements and the residuum produced will vary ${ }^{(12,13)}$. Feedstock crude may vary significantly from different places in the world, or different places in the same oil field. Another problem with asphalt fume sampling is the variation within the same lot of asphalt (i.e. the mixture is 
not homogeneous $)^{(14)}$. The heterogeneous nature may help explain some difference in analytical results reported between laboratory and field samples. Generally, the laboratory generated fume samples come from static, heated asphalt sources that were stirred. In the field no such stirring takes place and fumes are generated from a non-static source. The fume is generated at the surface of the asphalt and stirring may alter the fume by bring pockets of trap volatilized compounds to the surface.

A variety of extraction and analysis methods are available for PAHs. For example, the NIOSH standard method for total PAHs (PACs) uses a cyano (CN) solid phase extraction (SPE) column followed by liquid:liquid extraction into dimethylsulphoxide (DMSO) ${ }^{(15)}$. The liquid:liquid extraction transfers the PAHs in a non-volatile solvent appropriate for simple spectrofluormetric analyses but difficult to concentrate for trace analyses. A complex mixture, such as asphalt fume extract contains compounds causing interference with analyses by having similar physical/chemical properties to the compounds of interest. Several studies have used fluorescence techniques to identify PAH compounds ${ }^{(16,17)}$. This again poses a problem when applied to a complex mixture. Many compounds fluoresce at wavelengths similar to the compounds of interest. Substituted PAHs may fluoresce with slightly different properties than those of the standard PAHs and thus provide poor qualitative and quantitative estimates of the content of classes of compounds.

The compounds of concern in the present study are PAHs. A PAH is a compound with two or more six- or five-membered rings with annellation either being linear or angled (angles always add to $120^{\circ}$ ). Just considering the two to eight, six-member ring PAHs there are 1896 possible combinations. EPA Method 610 defines sixteen of these compounds as priority pollutants. The properties of a PAH depend on its size (number of rings) and the topology of the system (type of ring linkage) ${ }^{(18)}$. Another chemical property of a PAH is the reactivity of its highest occupied molecular orbital. This property makes it a Lewis base and allows it to stabilize according to the Lewis Octet Theory. More specifically a PAH behaves as an electron rich pi-system ${ }^{(17)}$. PAH compounds are also known to have acutely toxic effects and/or have mutagenic, 
teratogenic, or carcinogenic properties ${ }^{(19,20)}$. Some PAHs are metabolized to carcinogenic species. The classic example is benzo[a] pyrene- 7,8-diol-9,10-epoxide, (see Figure 1). So several of the PAH are procarcinogens. In the substitution reactions typical for PAH compounds, the hydrocarbon acts as a nucleophile; the bases of DNA are also nucleophiles so binding does not take place. The opening of the epoxide ring causes an electrophilic system, which can then react with DNA, causing DNA adducts and transcriptual errors ${ }^{(18,21)}$. A simplified metabolic pathway can be seen in Figure 2.

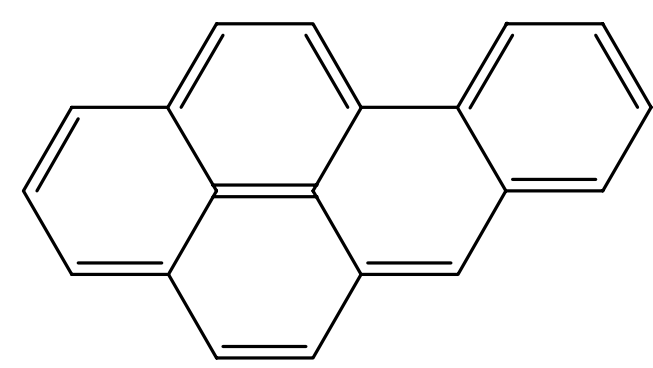

Benzo(a)pyrene

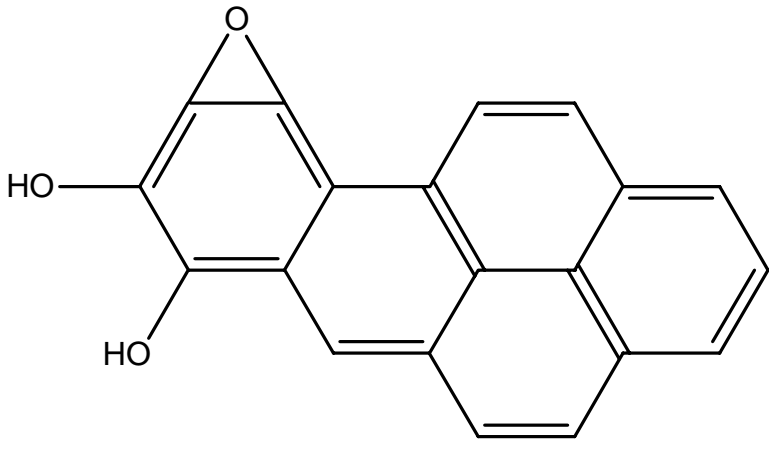

benzo(a)pyrene 7,8 diol 9,10 epoxide

Figure 1- benzo(a)pyrene gets metabolically converted to mutagenic BPDE through several metabolic steps. 


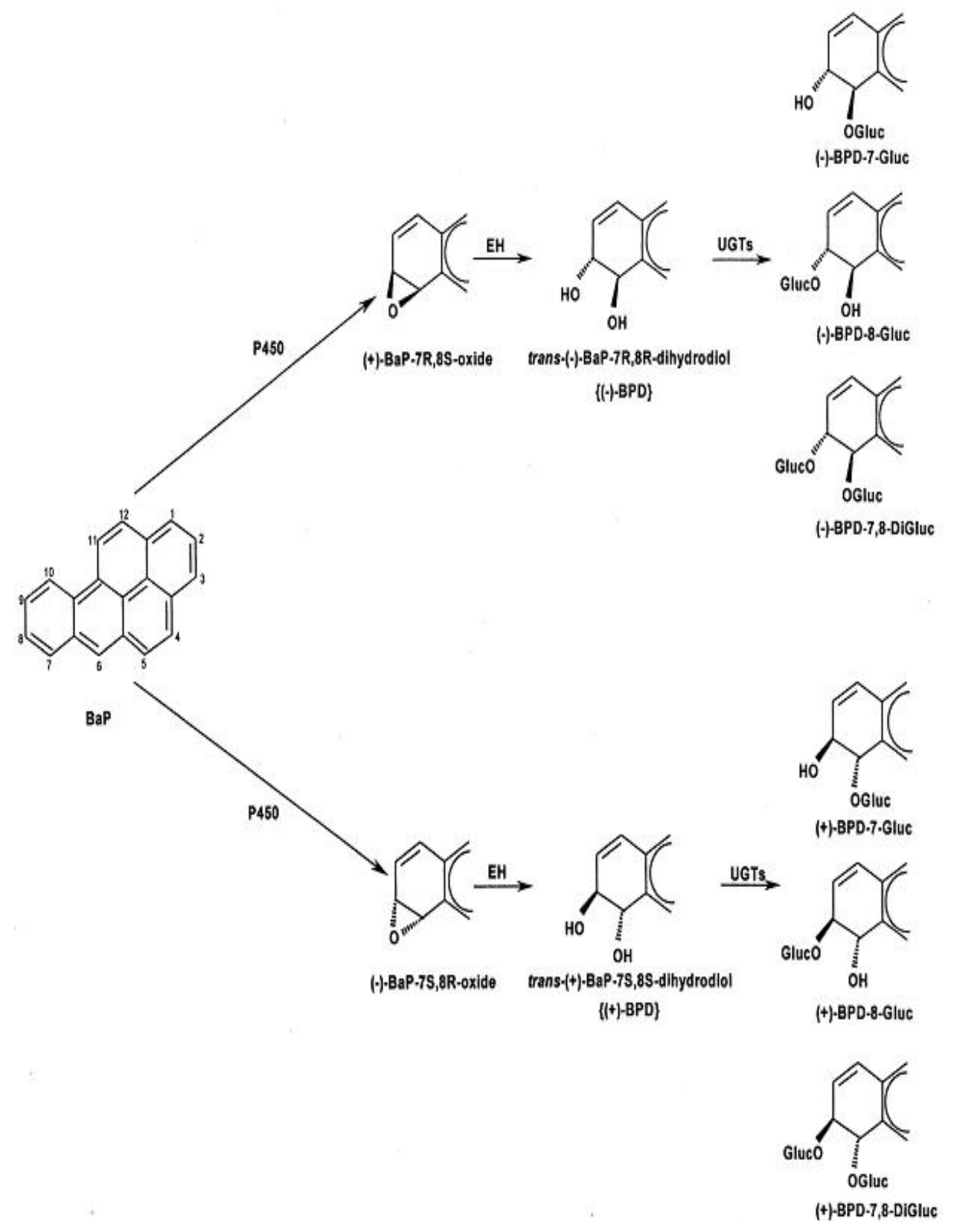

Figure 2- 1A simplified illustration of the metabolism of B[a]P. Copyright $@ 2002$ American Association for Cancer Research ${ }^{(22)}$.

PAH compounds are products of incomplete combustion of fossil fuels and other organic material. They are natural constituents in fossil fuels and are therefore present in relatively high concentrations in products of fossil fuel refining ${ }^{(23,24,25)}$. Asphalt is the residue left after all other refined products are processed from crude oil. 
The potential health risk due to exposure to asphalt fume from paving operations is not known. A study done by the Asphalt Association in 1975 found no significant air pollution problems were associated with emissions from hot paving operations $^{(26)}$. Reinke et al. ${ }^{(27)}$ reported that asphalt fume condensates collected from a commercial operation were not mutagenic.

Reinke and Swanson collected paving asphalt fumes from a straight-reduced, vacuum-processed 85-100 grade asphalt cement. They also collected fumes from a storage tank at a hotmix plant maintained at a temperature of $149^{\circ} \mathrm{C}\left(300^{\circ} \mathrm{F}\right)$ and from laboratory generation at temperatures of $149^{\circ} \mathrm{C}$ and $316^{\circ} \mathrm{C}\left(300\right.$ and $\left.601{ }^{\circ} \mathrm{F}\right)$. The fume samples were then analyzed for selected PAHs. The results indicate that only two- and three-ring PAHs were present in the fumes from the storage tank and laboratorygenerated fumes were predominately two- and three-ring PAHs, and also contained a few three-ring sulfur-PAHs (S-PAHs) and four-ring PAHs. Several of the four-ring PAHs found are carcinogenic, i.e., benz[a]anthracene and chrysene. Methylated chrysenes, pyrenes, and fluoranthenes were also detected and may be of concern because of their structural relationship to known carcinogens. The concentration of four-ring PAHs was highest in fumes generated in the laboratory at the highest temperature. Paradoxically, the concentration of two ring PAHs was lowest in laboratory fumes generated at the highest temperature, most abundant in fumes from the storage tank, and lower in the fumes generated in the laboratory at the ambient temperature of the storage tank ${ }^{(27)}$. It must also be noted that the analytical methodology consisted only of basic sample extraction into dichloromethane and direct injection onto a tabletop GC-MS. The absence of cleanup and concentration of such a complex mixture raises questions concerning the validity of the results.

Watts and colleagues ${ }^{(28)}$ measured the mean concentrations of airborne particles $(2.5 \mu \mathrm{m})$ at three different paving sites in the United States and observed an exposure range of $111-389 \mu \mathrm{g} / \mathrm{m}^{3}$. Burstyn and coworkers ${ }^{(29)}$ compiled data from several countries and studies and reported that European road paving workers can be exposed to 0.1-2 $\mathrm{mg} / \mathrm{m}^{3}$ of bitumen fume, which may contain $10-200 \mathrm{ng} / \mathrm{m}^{3}$ benzo[a]pyrene. The study 
involved data from many different samples mostly from industrial hygiene surveys for compliance. Asphalt temperatures probably varied greatly between these studies. Measurements of B(a)P and bitumen fume were based on a variety of methods. Again raising questions on the validity of the results. Although normal exposure levels to road paving asphalt fumes are relatively low, long-term health effects associated with chronic exposure may be a concern ${ }^{(30)}$.

The asphalt fume from paving operations has been described as nonmutagenic ${ }^{(31)}$. Probably the greatest contributing factor to this is the temperature at which road paving asphalt is applied. The heavy PAHs have higher boiling points and thus do not readily volatilize at the lower road paving temperatures temperatures. Several heavy PAHs are known to be mutagenic and carcinogenic. Evidence suggests in some cases PAH genotoxicity increases with size ${ }^{(32)}$. Smaller, lighter PAHs are generally considered irritants, with the exception of naphthalene. In a two-year naphthalene inhalation study by the National Toxicology Program (NTP), it was concluded there was clear evidence of an increased incidences of respiratory epithelial adenoma and olfactory epithelial neuroblastoma of the nose in $\mathrm{F} 344 / \mathrm{N}$ rats, both male and female ${ }^{(33)}$. A previous study study showed an increase number of lung cancers in female B6C3F mice ${ }^{(34)}$. Paving workers are generally not exposed to just asphalt fume. It must be considered that these workers are exposed to diesel exhaust, gasoline engine exhaust, and ultra violet radiation concomitantly with the asphalt fume.

Due to the presence of PAHs in asphalt fume, the potential mutagenic/carcinogenic effects have been the central focus of in vitro ${ }^{(35,36)}$, in vivo animal $^{(37,38,39)}$, and worker studies ${ }^{(40)}$. Other health effects may be associated with acute asphalt fume exposure. Norseth et al. ${ }^{(41)}$ reported that, during road repair and construction, asphalt workers experienced abnormal fatigue, reduced appetite, eye irritation, and laryngeal/pharyngeal irritation. The frequency of symptoms reported increased with increasing asphalt fume generation temperature above $150{ }^{\circ} \mathrm{C}$. An epidemiologic study has reported an increase of nonmalignant lung diseases, such as bronchitis and emphysema, among California highway workers ${ }^{(42)}$. The association 
between road paving temperature and potential health effects has not been clearly

established. A major road blocks to the study of health risk to asphalt fumes has been the variability of components of asphalt fume and the lack of sensitive, specific analytical methods to properly characterize the exposures. 


\section{Materials and Methods}

\subsection{Asphalt Fume Generation, Sample Collection, and Extraction}

The asphalt fume generation system was designed to simulate the road paving process. The oven (Grieve, Round Lake, IL ) heated three five-gallon buckets of asphalt to a temperature of $190^{\circ} \mathrm{C}$. Liquid asphalt flowed into a custom fabricated storage pan in the bottom of the oven as it was heated. Asphalt temperature was maintained with a single on/off temperature controller and two 500 watt heaters attached to the pan. An asphalt pump (Roper, Commerce, GA), coupled to a 1 HP motor (General Electric 5KCR48UN0102X, @1725 RPM), transferred the liquid asphalt from the pan to a specially designed bitumen kettle. The plumbing between the pump and the kettle was wrapped in 500-watt heat tape to prevent the subsequent cooling of the liquid asphalt. A 750-watt heater was used to maintain the temperature of the asphalt in the kettle. An ultrasonic sensor provided feedback of the asphalt level in the kettle to prevent overfilling. The purpose of the kettle was to maintain a smooth flow of asphalt across the fume generator. A more consistent asphalt flow was obtained by pumping into the bitumen kettle, rather then directly controlling the asphalt pump. Asphalt from the bitumen kettle flowed through a needle valve which was part of a computer feedback system used to regulate asphalt flow. The plumbing between the kettle, needle valve, and generator was wrapped with 500-watt heat tape. Next, the asphalt entered the stainless steel fume generator chamber where it spread over a rectangular plate (6" x 24 ") that simulated application of asphalt to a road surface. It then passed through a trap and emptied into a container resting on a scale. Incremental scale readings of the container weight were used in a computer controlled feedback loop to achieve a constant mass flow of asphalt $(150 \mathrm{mg} / \mathrm{min})$ through the needle valve. A 750-watt heater and an on/off controller were used to maintain an asphalt temperature gradient of $150{ }^{\circ} \mathrm{C}$ to $125{ }^{\circ} \mathrm{C}$ $\left(180{ }^{\circ} \mathrm{C}\right.$ to $150{ }^{\circ} \mathrm{C}$ for $180^{\circ} \mathrm{C}$ asphalt fume generation temperature) across the generator 
bed. The asphalt was cooled as HEPA filtered air $\left(25^{\circ} \mathrm{C}, 50 \% \mathrm{RH}, 20 \mathrm{lpm}\right.$ passed over the bed and entrained the asphalt fume. The inlet and outlet temperatures of the asphalt, as it passed over the plate, were measured with J-type thermocouples positioned 1" from the generator inlet and outlet, respectively. Temperatures through the system were adjusted to obtain the desired asphalt temperature $\left(150{ }^{\circ} \mathrm{C}\right.$ or $\left.180{ }^{\circ} \mathrm{C}\right)$ for a given experiment. Fume produced in the generator was transported to the exposure chamber and through the use of a series of heat tapes, gradually cooled to a temperature of around $25^{\circ} \mathrm{C}$. A diagram of the generation system is illustrated in Figure 3.

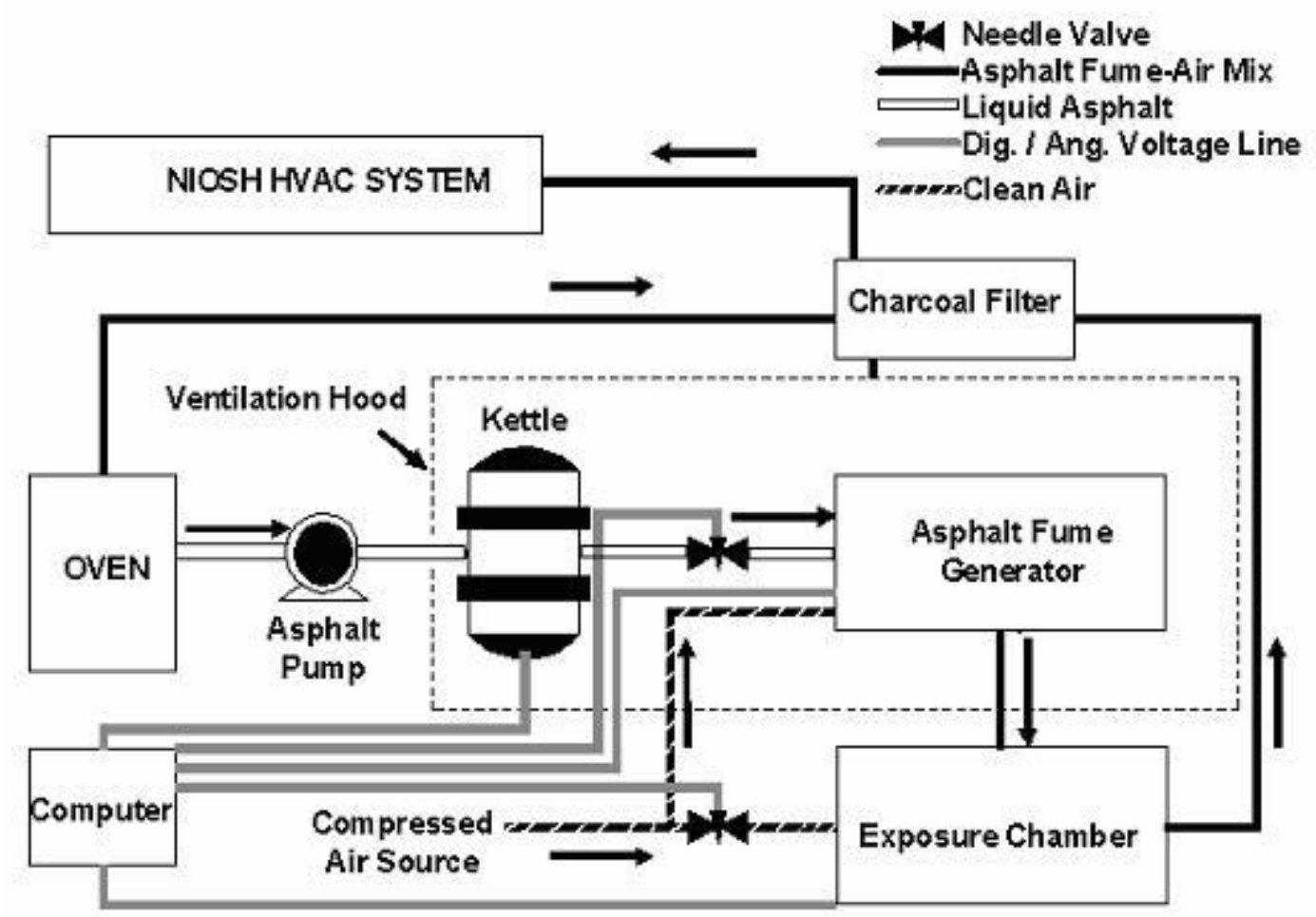

Figure 3- A diagram of the simulated paving asphalt fume generator system.

The sampling train consisted of a $63 \mathrm{~mm}$ glass fiber HEPA filter followed by $10 \mathrm{~g}$ of XAD (Supelco, Bellefonte, PA) resin. Samples were collected at $10 \mathrm{lpm}$ for $240 \mathrm{~min}$. $\mathrm{XAD}$ samples were stored at $-20{ }^{\circ} \mathrm{C}$ in amber glass bottles with polytetrafluoroethylene (PTFE) lined lids until extraction. The mass of XAD recovered from each sampler was determined gravimetrically and recorded. Filters were labeled and stored at $-20{ }^{\circ} \mathrm{C}$ in the 
dark in zipper closed plastic bags. Extraction of XAD and filters consisted of a one-hour gentle vortexing at approximately 100 RPM using dichloromethane (DCM) as the extraction solvent. Filters were extracted in $50 \mathrm{ml}$ of DCM each. XAD samples were extracted in $250 \mathrm{ml}$ of DCM per each XAD sample. Extracts were filtered through 0.2 $\mu \mathrm{m}$ HF membranes (Millipore, Billerica, Ma) using a vacuum flask apparatus. Solvent recovery was measured using a graduated cylinder and recorded. The extracts were stored in amber serum bottles with crimped PTFE lined lids. All crude sample extracts were stored at $-20{ }^{\circ} \mathrm{C}$ to prevent evaporation and UV degradation. Breakthrough was not accessed in this set of samples; however, in preliminary runs a small XAD tube was used to sample the effluent air at $1 \mathrm{lpm}$ after the high volume sampler, and breakthrough was not detected. Total fume concentration, simulated boiling point profiles, and naphthalene concentrations were determined using these crude extracts, without additional sample manipulation.

\subsection{Purification Methods Development}

The preparatory high performance liquid chromatographic (HPLC) method used to separate PAHs from aliphatic interferences is a modification of that used to clean-up

diesel fume extracts for PAH analyses reported by Jiao, et.al. ${ }^{(43)}$. This HPLC method employed a poly- divinylbenzene (PDVB) gel solid phase column. To develop the preparatory HPLC method several standards were employed. To simulate asphalt fume extracts a kerosene reference standard and a PAH cocktail were mixed. Kerosene is a good substitute for the aliphatic compounds that interfere with asphalt analysis, but like asphalt, kerosene also contains other compounds. The QTM mixture (Supelco \#47930U) contains 16 PAH compounds which the EPA consider significant. The first attempts at developing this method used an isocratic (constant concentration) flow of different hexane and dichloromethane concentrations. Fluorescent and photo diode array detectors were employed to establish the solvent gradient profile that provided the optimal conditions for fraction collection. 


\subsection{High Performance Liquid Chromatographic Fractionation for PAHs.}

Internal standards, $20 \mu \mathrm{g}$, each, of naphthalene- $d_{8}$, acenaphthene- $d_{10}$, chrysene$d_{12}$, benzo [a] pyrene- $d_{12}$ (Cambridge Isotope Laboratories, Andover MA) were added to $25 \mathrm{ml}$ of each filter sample DCM extract. Twenty micrograms of naphthalene- $d_{8}$ and acenaphthene- $d_{10}$ were added to $25 \mathrm{ml}$ of each XAD sample extract. XAD and filter samples were concentrated 125 fold by evaporation under $\mathrm{N}_{2}$ at room temperature and reconstituted in 200 ul DCM. Aliphatic compounds are retained by PDVB gel using steric features such as size and shape of the molecule, PAH compounds are retained, preferentially, via Lewis acid-base interactions. The method utilizes a $500 \mathrm{~mm} \times 10 \mathrm{~mm}$, $500 \AA ̊$ poly- divinylbenzene (PDVB) gel HPLC column (Alltech, Deerfield, IL). Concentrated DCM extracts $(200 \mu \mathrm{l})$, were injected onto the PDVB column in $100 \mu \mathrm{l}$ aliquots (2 separate HPLC runs each). PAH standards (Supelco, Bellefonte, PA) were prepared and processed in parallel to the asphalt fume samples. Initially, the column was washed with $100 \%$ hexane for 25 minutes at $1 \mathrm{ml} / \mathrm{min}$ to remove aliphatics, followed by a rapid linear gradient over the next minute to $100 \%$ DCM to elute the PAHs. A fluorescent detector set to an excitation wavelength of $254 \mathrm{~nm}$ and an emission wavelength of $400 \mathrm{~nm}$ was used to monitor elution of PAHs. Aliphatic compounds were monitored using a GBC LC5000 photodiode array (PDA) scanning the UV range.

Fraction collection was done using a manual six-port valve. The valve was opened at 50 minutes post-injection (approximately 1 minute before elution of PAH compounds as determined by preliminary studies using standard QTM PAH standard mixture (Supelco, Bellefonte, PA). The fraction was collected until the fluorescent detector had returned to baseline (approximately $25 \mathrm{ml}$ ). This fraction was evaporated to dryness under nitrogen and reconstituted to $100 \mu \mathrm{l}$ in DCM for gas chromatograpic-mass spectrometry (GCMS) analyses. Table I summarizes the solvent gradient used. 
Table I. Summary of HPLC Conditions

0-30 min - 100\% Hexane

30-31 min- 100\% Hexane to 100\% Methylene Chloride

31-75 min- 100\% Methylene Chloride

75-76 min- 100\% Methylene Chloride to $100 \%$ Hexane

$\mathrm{XAD}$ and filter PAH fractions were kept in sealed, amber glass vials with PTFE septa at $-20{ }^{\circ} \mathrm{C}$. XAD samples were used to analyze the vapor portion of the fume, especially naphthalene. Naphthalene was identified and quantified from crude DCM extracts because (1) it was lost during solvent evaporation under nitrogen and (2) it was present as sufficient levels in the XAD fraction to analyze directly by GC/MS without further sample clean-up.

\subsection{Gas Chromatography and Mass Spectrometry Procedures}

The specific compounds were accessed by GC/MS-selected ion-monitoring mode (SIM), using a 5972 series GC/MS, (Agilent Technologies, Palo Alto, CA). The compounds monitored were naphthalene, acenaphthylene, 2-bromonaphthylene, acenaphthene, fluorene, phenanthrene, anthracene, fluoranthene, pyrene, benzo(a)anthracene, chrysene, benzo-(b)fluoranthene, benzo(A)pyrene, benzo(ghi)perylene, indeno(1,2,3-cd)pyrene, and dibenzo(a,h)anthracene. The monitored mass-to-charge ratios $(\mathrm{m} / \mathrm{z})$ are listed in Table II. Electron impact ionization (EI, 70eV) MS was used to analyze samples, standards, and blanks. Data acquisition and processing were performed within the ChemStation software suite (Agilent Technologies, Palo Alto, $\mathrm{CA})$. The GC column was an HP-5MS ( $30 \mathrm{~m} \times 0.25 \mathrm{~mm}, 0.25 \mu \mathrm{m}$ film thickness) fused silica capillary (J\&W Scientific, Folsom, CA). Seperation by this column is based on the boiling point of the analyte (higher boiling point compounds have greater retention). Analytes were eluted using ultra high purity (UHP) helium as the carrier gas at $1 \mathrm{ml} / \mathrm{min}$. Following the $1 \mu \mathrm{l}$, splitless injection, the $\mathrm{GC}$ oven was held at $50{ }^{\circ} \mathrm{C}$ for two minutes; the temperature was then increased by $5{ }^{\circ} \mathrm{C} / \mathrm{min}$ to a final temperature of $310{ }^{\circ} \mathrm{C}$ and held for 
1 minute (for a total run time of $55 \mathrm{~min}$ ). A summary of GC/MS conditions can be found in Table III.

Table II. Ions Monitored by GC/MS Analysis, SIM Mode.

\begin{tabular}{llll}
\hline PAHs & Ions $(\mathrm{m} / \mathrm{z})$ & PAHs & Ions $(\mathrm{m} / \mathrm{z})$ \\
\hline Naphthalene & 127127,102 & Benzo[a]anthracene & $228,226,229$ \\
Acenaphthylene & $152,151,160$ & Chrysene & $228,229,226$ \\
2-bromonaphthylene & $127,206,208$ & Benzo[b]fluoranthene & $252,253,126$ \\
Acenaphthene & $153,154,152$ & Benzo[a]pyrene & $252,250,264$ \\
Fluorene & $166,165,167$ & Dibenzo [a,h]anthracen $278,279,276$ \\
Phenanthrene & $178,176,179$ & Indeno[1,2,3-cd]pyrene & $276,137,227$ \\
Anthracene & $178,176,179$ & Benzo[ghi]perylene & $274,138,288$ \\
Fluoranthene & $202,200,201$ & & \\
Pyrene & $202,203,200$ & & \\
\hline
\end{tabular}

Table III. Summary of Gas Chromatogrpahy and Mass Spectrometry Conditions

Inlet $\mathrm{B}$ Temperature- $250^{\circ} \mathrm{C}$

Detector B Temp- $280^{\circ} \mathrm{C}$

Initial Oven Temp- $50^{\circ} \mathrm{C}$

Initial Time- $2.00 \mathrm{~min}$.

Oven Rate- $5^{\circ} \mathrm{C} / \mathrm{min}$

Final Temp $310^{\circ} \mathrm{C}, 55 \mathrm{~min}$

Constant Flow- $1 \mathrm{ml} / \mathrm{min}$

Injection Volume- $1 \mathrm{ul}$

Identification of specific PAH compounds present in the sample extracts was based on the relative abundance ratios of selected ions, as well as, relative retention times (RRT's) of the target analytes relative to the deuterated internal standards. The ion ratios of a specific PAH within $25 \%$ of its respective standard were required for positive identification. Filter, XAD, and solvent blanks were run for all analyses.

Total vapor and particulate fume concentrations and boiling point profiles were determined using the GC/MS in the total ion monitoring mode, and the above GC conditions. The total ion chromatogram (TIC) generated by this technique does not resolve individual compounds from this complex mixture. The sum of the total ions from the TIC of the unresolved fume eluted from the GC column were integrated to quantify 
the fume concentration. The vapor fraction concentration was determined relative to a kerosene standard (47517-u, Supelco, Bellefonte, PA). The particulate fraction was quantified against neat asphalt fume filter DCM extract for which the density was measured to be $1.84 \mathrm{~g} / \mathrm{ml}$ by gravimetric analyses. The boiling points of naphthalene, acenaphthene, phenanthrene, benz(a)anthracene, and benzo(a)pyrene were plotted against retention time of the respective PAH compounds. The equation of the line $(y=8.8934 x$ +86.923 ) was used to extrapolate retention time to boiling point to determine the boiling point profiles of the fume fractions. Boiling point profiles and fume concentration were both determined from sample media DCM extracts (without any concentration or cleanup steps prior to GC/MS analysis). A summary of the methods are shown in Figure 4.

\subsection{Evaluation of Standards}

Three standards were evaluated using response factors compared to asphalt fume filter DCM extract. The analytical standards were chosen by their chemical composition. These standards were a reference kerosene standard (Supelco Inc), aliphatic standard mixture $\left(\mathrm{C}_{8}-\mathrm{C}_{36}\right)$ (Supelco Inc), and a PAH cocktail (Supelco Inc). Standard curves for each material were developed and an equation for each curve was derived. The concentration of the bulk asphalt fume was determined. After this determination, a response factor was derived by dividing the area under the curve (AUC) for each standard material by each concentration to yield an average $\mathrm{AUC} /$ mass of material. The results were averaged and then divided by AUC/mass of bulk asphalt fume. 


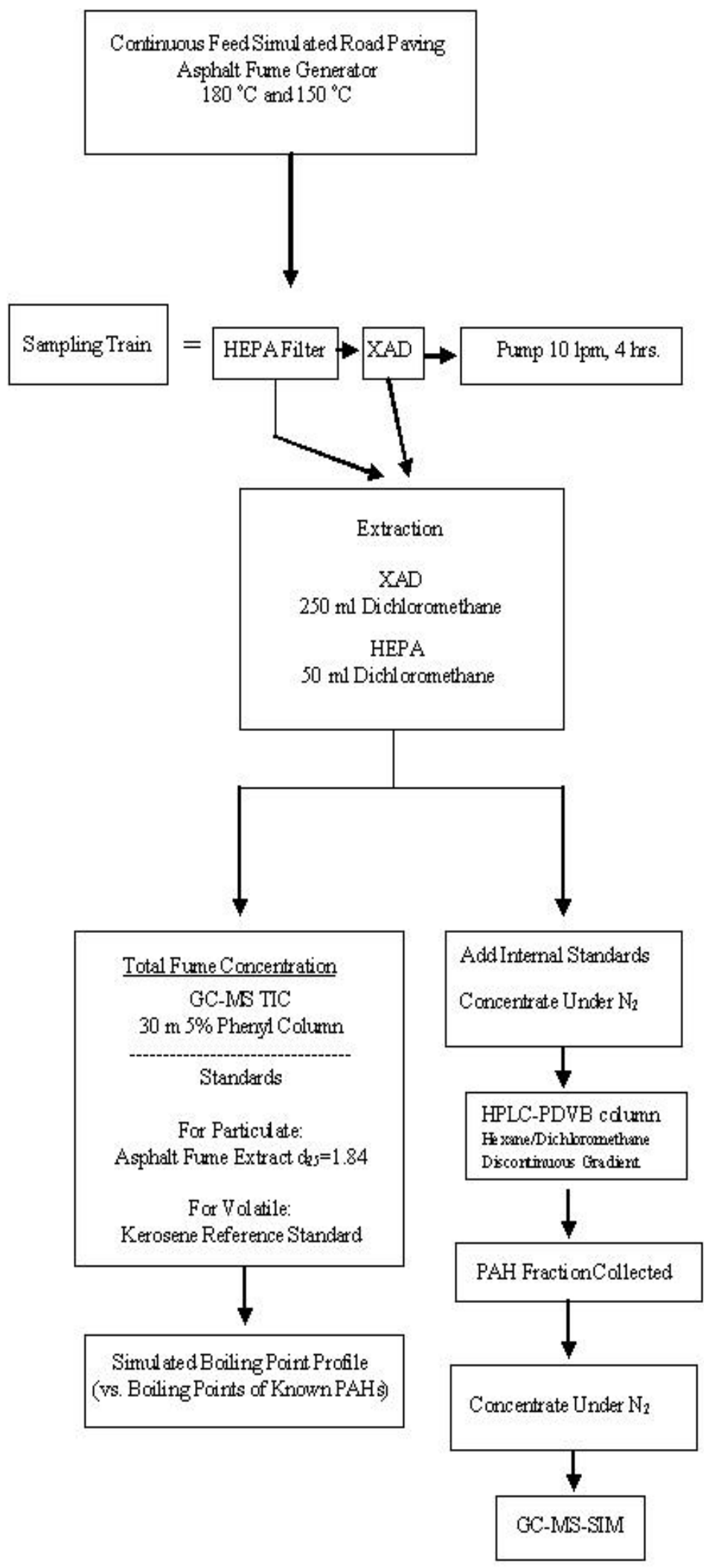

Figure 4- Diagram of the generation, collection, and analysis of the asphalt fume. 


\subsection{Fluorescence Techniques}

Pure mixtures of PAH compounds, including naphthalene, phenanthrene, pyrene, benzo[b]fluoranthene, and benzo[ghi]perylene were made in DCM. Each compound was diluted using DCM to $45 \mathrm{ng} / \mathrm{ml}$. Compounds were analyzed using a stand-alone spectrofluorometer (Perkin-Elmer, Wellesley, MA), in both a three-dimensional synchronous scanning mode and a set emission and excitation wavelength mode according to the NIOSH method $5800^{(15)}$. Asphalt fume condensate, particulate phase, extracts were diluted 1000 fold and analyzed in the same way. For the set wavelengths method the spectrofluorometer was set to an excitation wavelength of $254 \mathrm{~nm}$ and an emission wavelength of $370 \mathrm{~nm}$ for 2-4 ring PAHs, and $254 \mathrm{~nm}$ excitation $400 \mathrm{~nm}$ emission for 4-6 ring PAHs. Synchronous fluorescence spectra were collected by simultaneously scanning the excitation and emission monochromators in the 250-600 nm range with constant wavelength differences $\Delta \lambda$ according to the method of Apicella ${ }^{(44)}$. Fluorescence intensities were plotted as a function of the excitation wavelength. Four spectra were recorded for each sample with $\Delta \lambda$ of 10 ,

\subsection{Statistical Analysis}

Most of the statistics were performed using Microsoft $\subseteq$ Excel 2002 SP3. Statistical analyses consisted of the student unpaired t-Test with $\alpha$ equal to 0.05 in all instances to show statistical significance. This test was performed to analyze the difference between the groups of data being collected. A regression analysis was performed using SigmaStat v. 3.1 (Sysstat, Point Richmond, CA) on the curves produced for the boiling point profile. This test was done to provide a $95 \%$ confidence interval and compare boiling point distribution at the two generation temperatures. The geometric standard deviation was obtained from the boiling point profile curves by dividing the $84.13 \%$ of the cumulative ion amount by the mean mass boiling point. One standard deviation was used for error bars. 


\section{Results}

The effect of two different generation temperatures, $150^{\circ} \mathrm{C}$ and $180^{\circ} \mathrm{C}$, on the resultant fume was evaluated in the present study. Fume samples were collected from an environmental chamber onto a HEPA filter, followed by XAD resin material. The fumes were comprehensively characterized to allow for evaluation of fumes generated over the road paving temperature range. The particulate (HEPA filter) and vapor (XAD resin) fractions were analyzed from each sample to obtain (1) particulate, vapor and total asphalt fume chamber concentrations, (2) particulate and vapor components simulated boiling point profile, and (3) specific PAH content.

\subsection{Standards Comparison and Response Factors}

Response factors were developed after evaluating three standards used for quantification of total asphalt fume. Examples of the TIC can be seen in Figures 5-8. For the reference kerosene standard the response overestimated the particulate phase of the asphalt fume concentration by 1.8 times. For the PAH cocktail the curve overestimated the true concentration of the asphalt by 16.7 times. For the aliphatic mixture the overestimation was 1.7 times. The standard curves developed from the bulk asphalt fume, the kerosene reference standard, the PAH cocktail, and the aliphatic standard can be seen in Figures 9-12. Similar comparisons can not be made for the vapor fraction of the asphalt fume, because it is not possible to remove the extraction solvent without losing a substantial portion of the fume. 


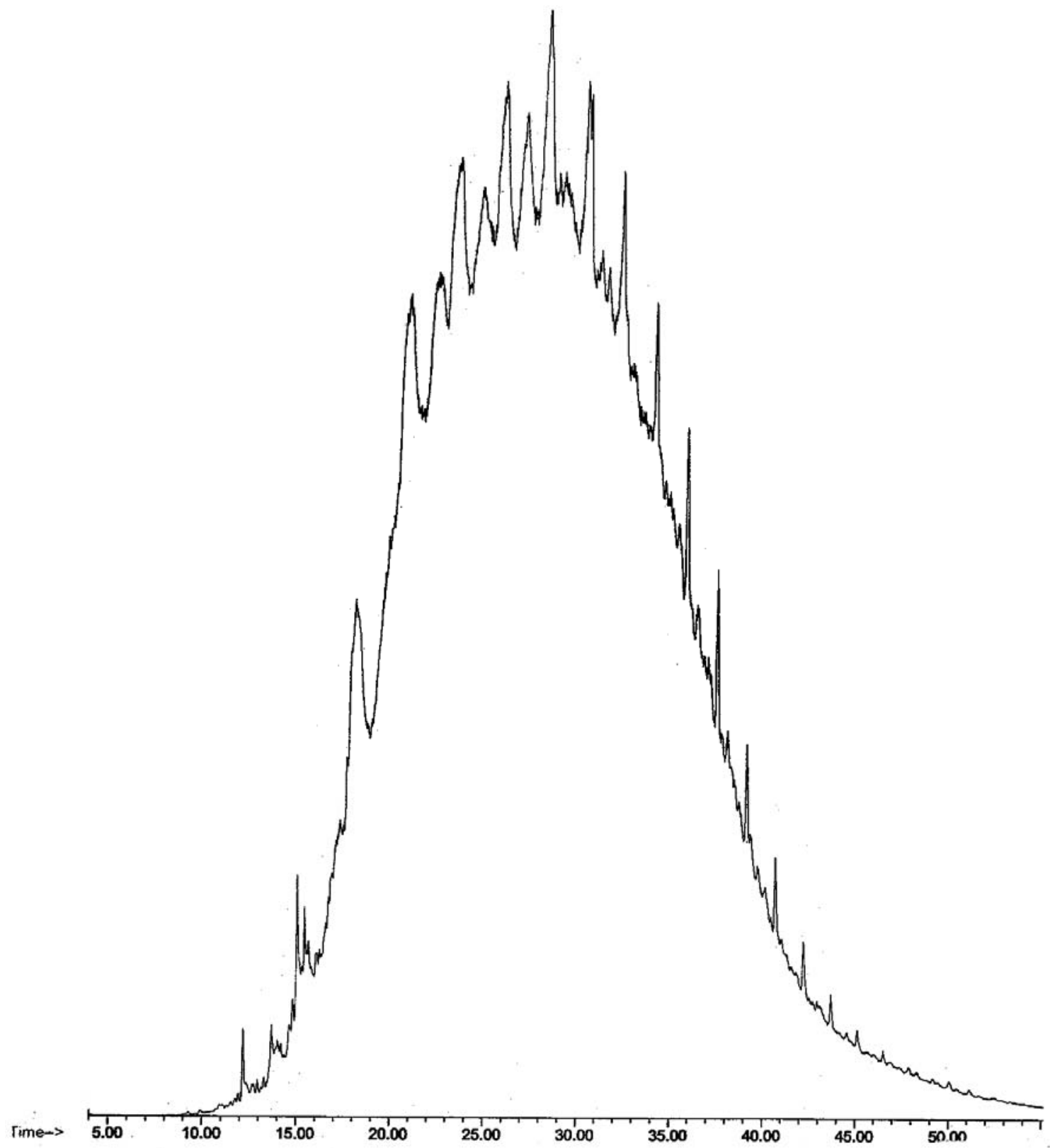

Figure 5- Bulk asphalt fume TIC. 


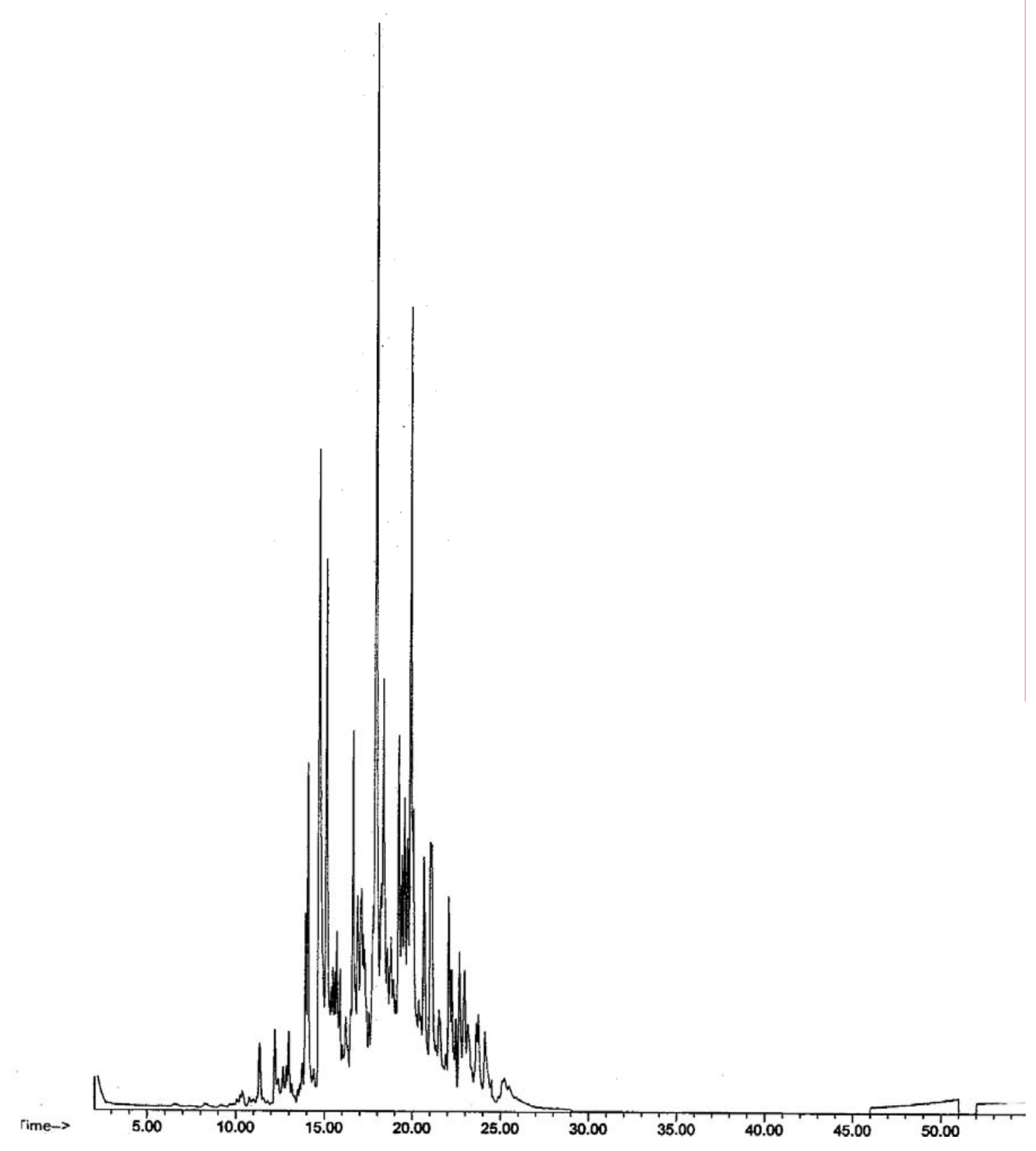

Figure 6- Reference standard kerosene TIC. 


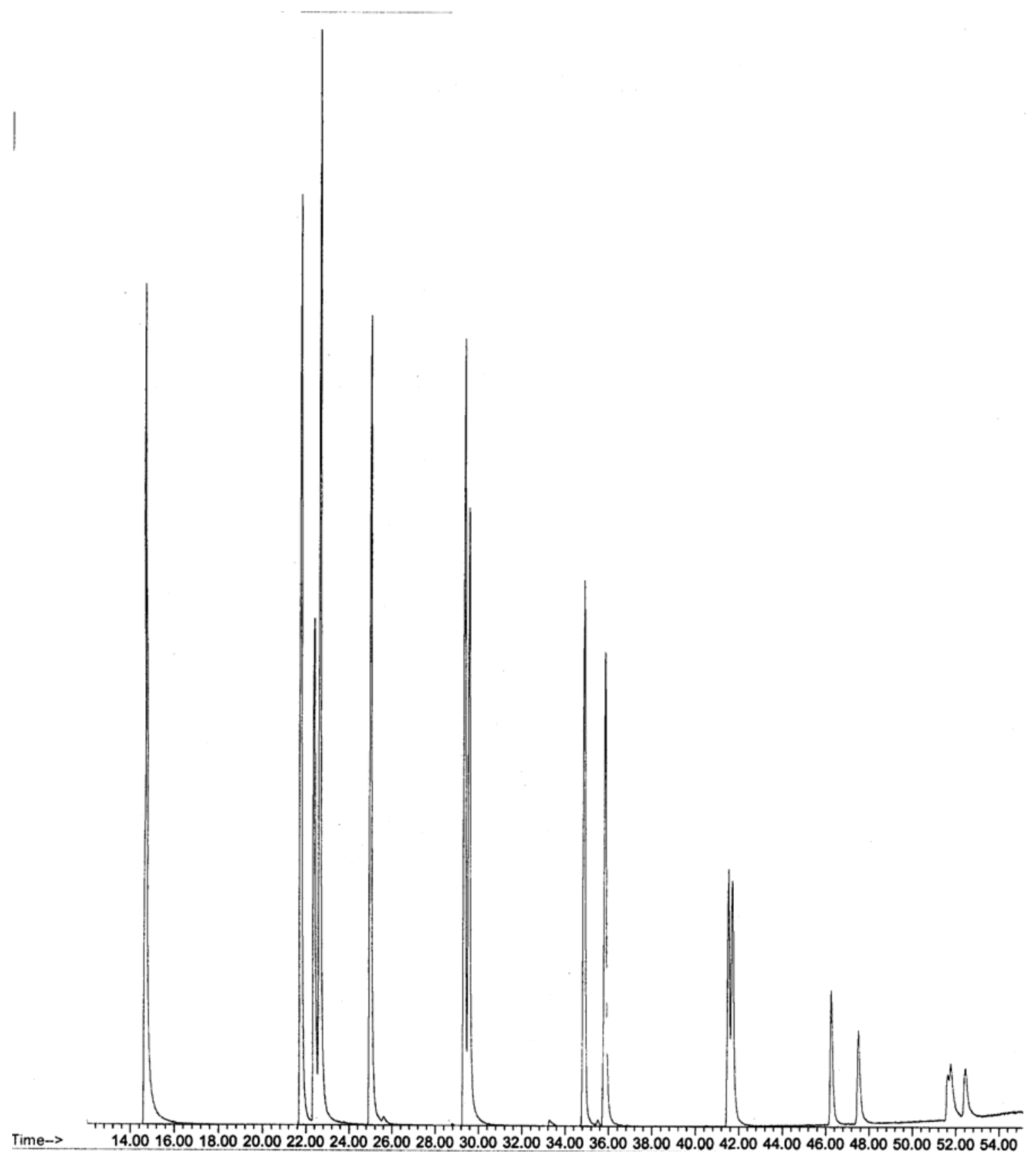

Figure 7- QTM PAH mixture TIC. 


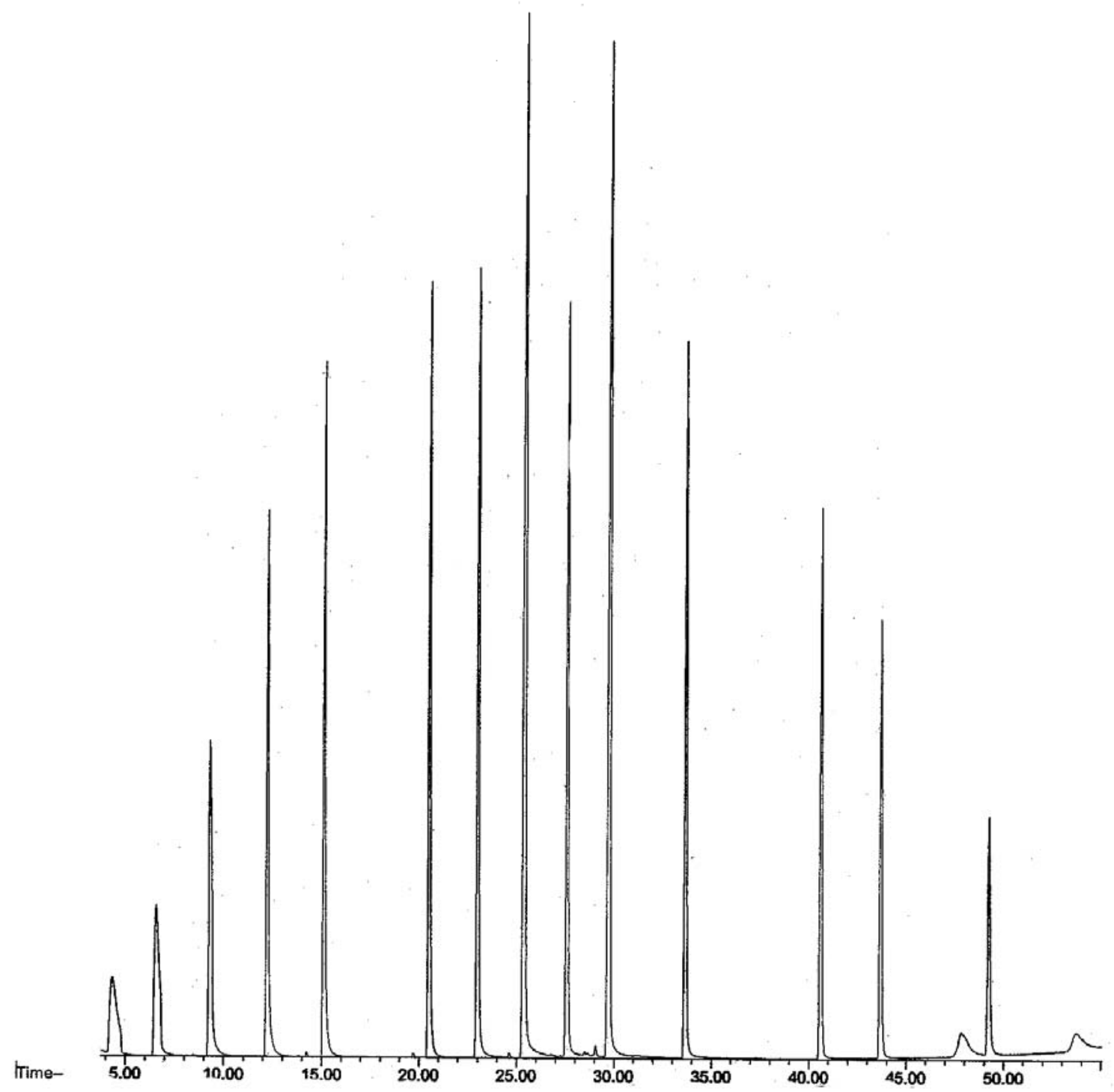

Figure 8- Aliphatic standard mixture TIC. 


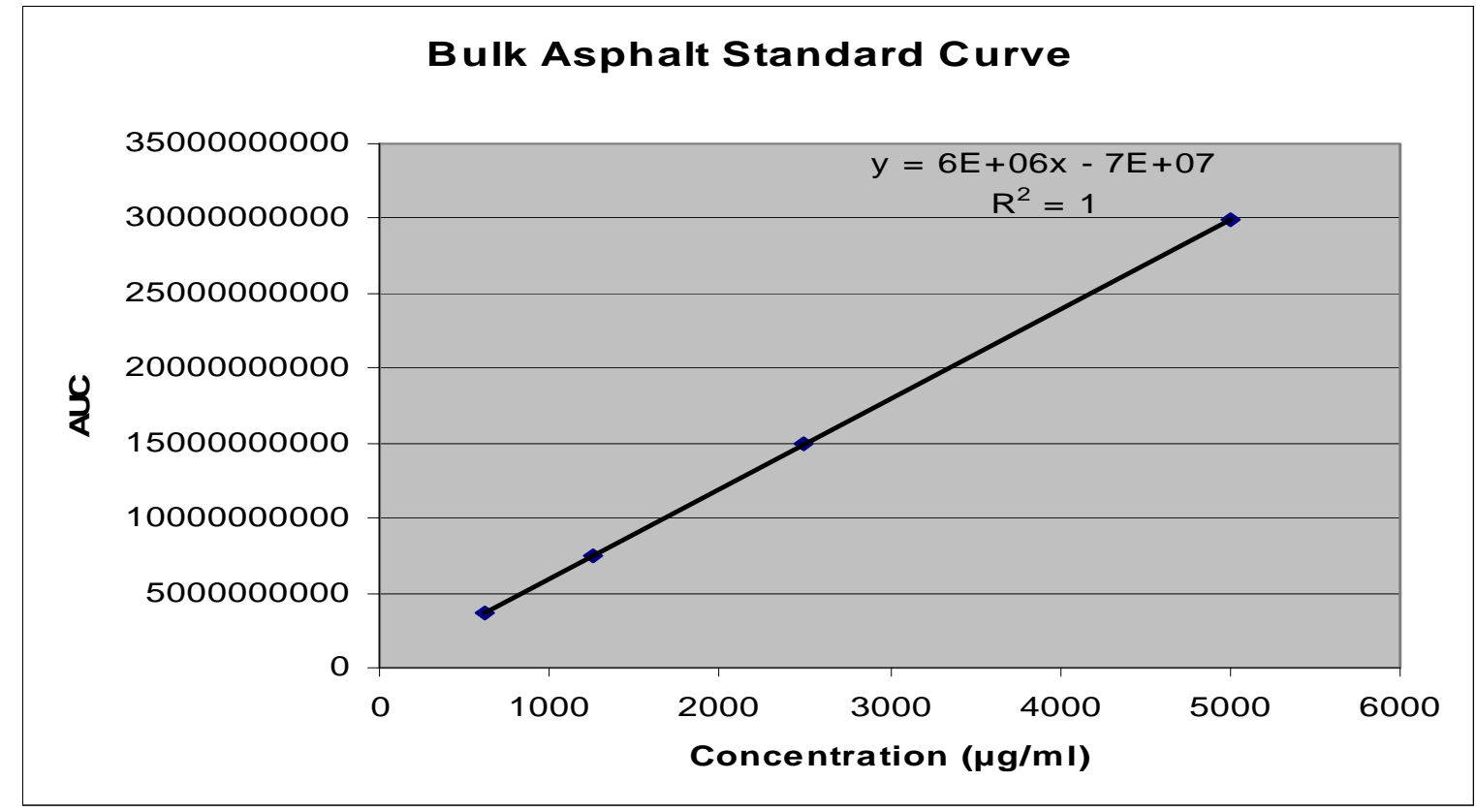

Figure 9- Bulk Asphalt GC/MS Standard Curve

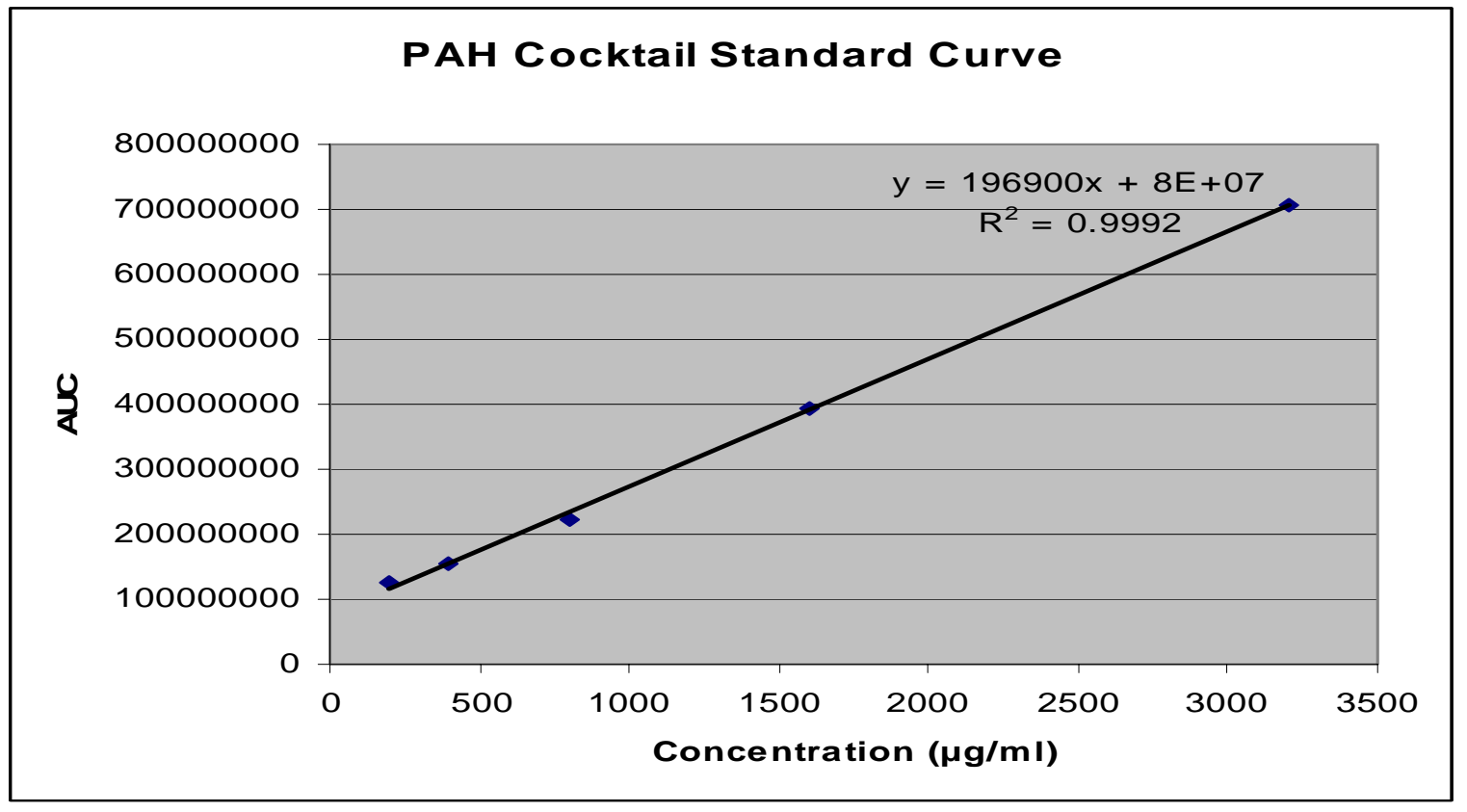

Figure 10- PAH Cocktail GC/MS Standard Curve 


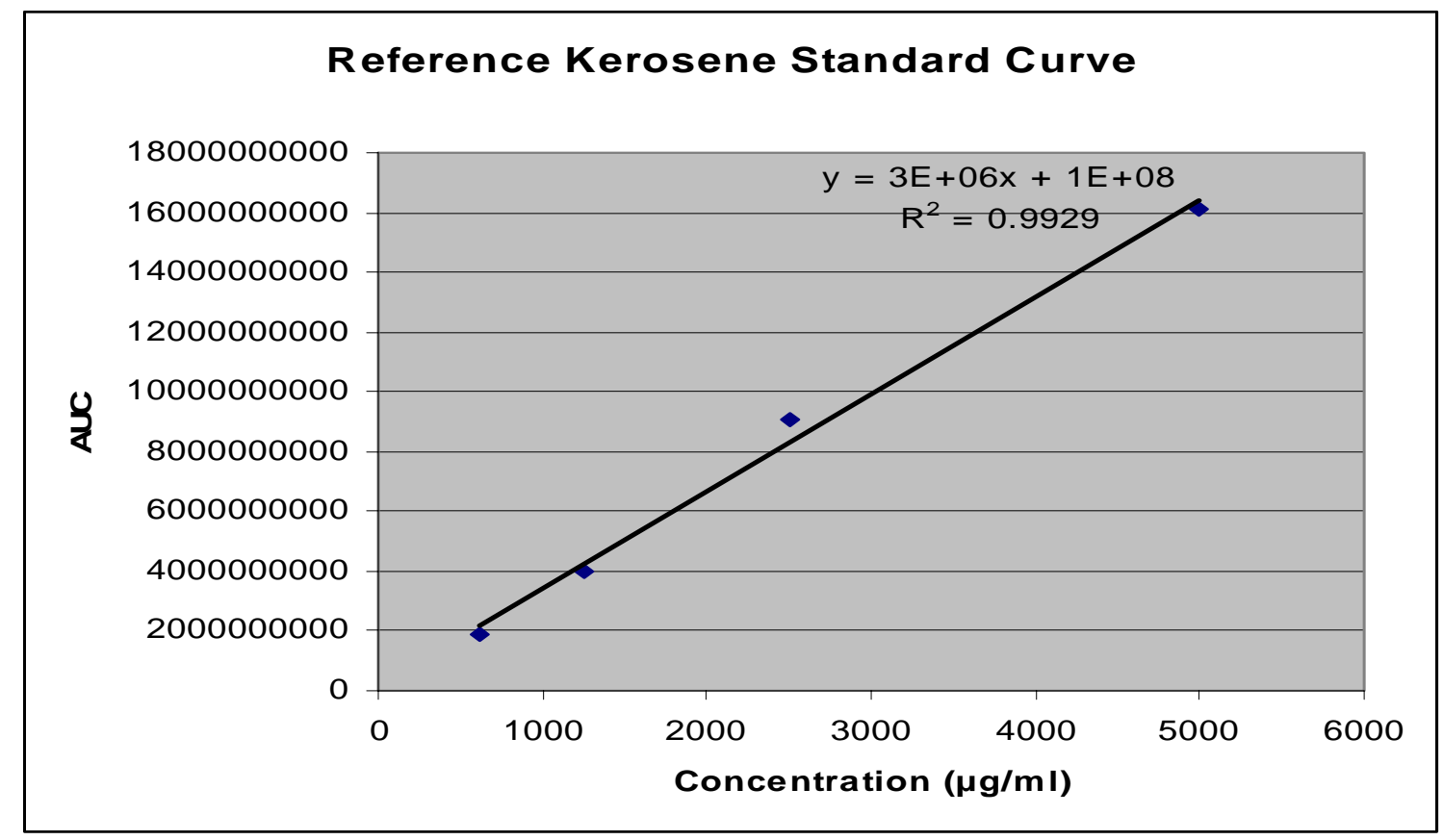

Figure 11- Reference Kerosene GC/MS Standard Curve

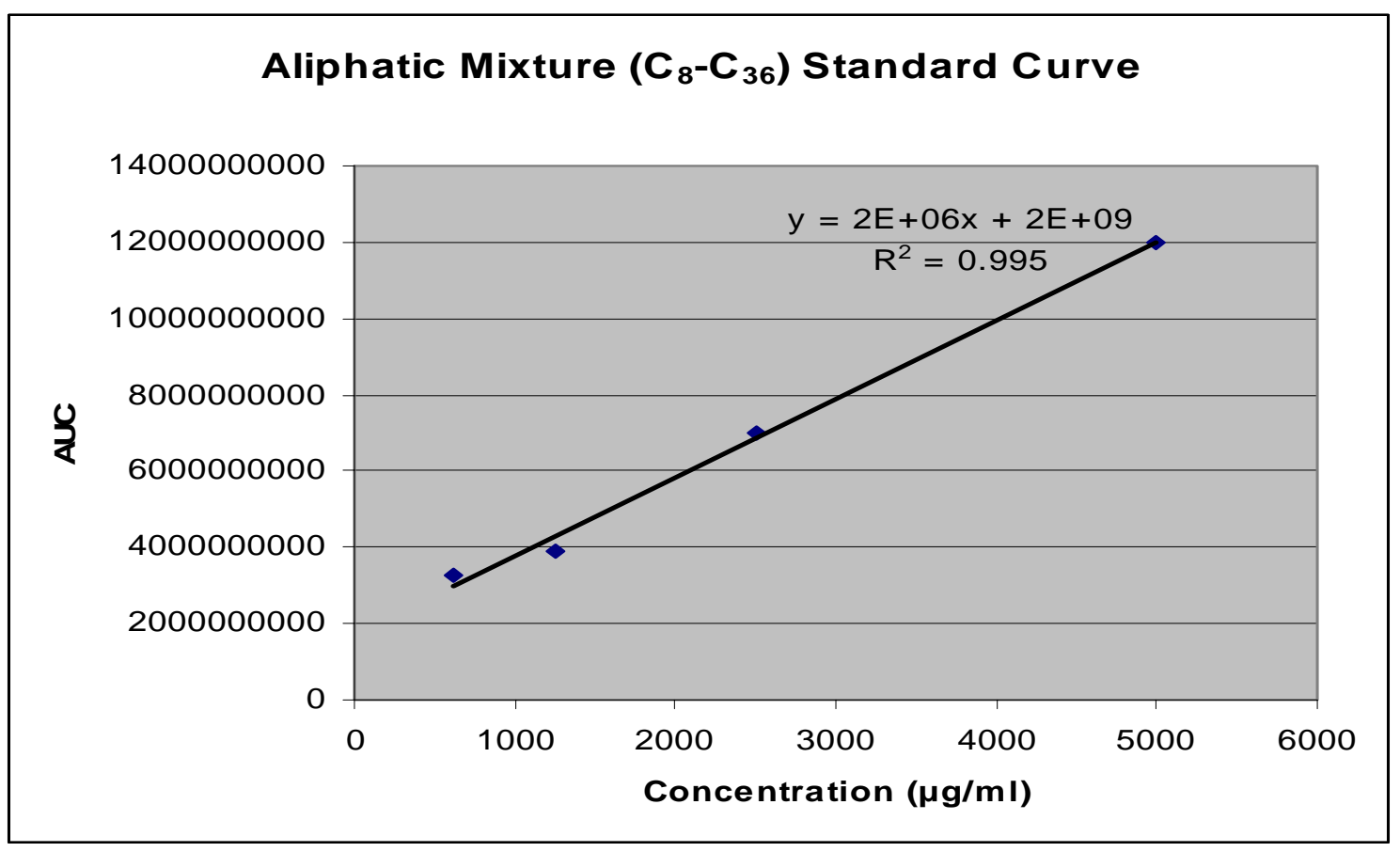

Figure 12- Aliphatic Mixture $\left(\mathrm{C}_{8}-\mathrm{C}_{36}\right)$ Standard Curve 


\subsection{Total, Vapor, and Particulate Asphalt Fume Chamber Concentrations}

Increasing the asphalt fume generation temperature from $150{ }^{\circ} \mathrm{C}$ to $180{ }^{\circ} \mathrm{C}$ caused a significant increase in the total fume air concentration $(p=0.02$, critical $T=2.4$, calculate $\mathrm{t}=3.1$ ), Figure 13. The mean total fume concentrations were $65.8 \pm 16.9 \mathrm{mg} / \mathrm{m}^{3}$ for the $180{ }^{\circ} \mathrm{C}$ fume and $39.3 \pm 2.6 \mathrm{mg} / \mathrm{m}^{3}$ for the $150{ }^{\circ} \mathrm{C}$ fume. Both the particulate and vapor fractions were elevated at $180{ }^{\circ} \mathrm{C}$ vs. $150{ }^{\circ} \mathrm{C}$ generation temperatures; however only the difference in the vapor fraction was statistically significant $(\mathrm{p}=0.02$, critical $\mathrm{T}$ value $=$ 2.4 , calculated $t$ value $=3.1$ ). The mean concentration of the vapor fractions generated at $180{ }^{\circ} \mathrm{C}$ and $150{ }^{\circ} \mathrm{C}$ were $23.3 \pm 6.6 \mathrm{mg} / \mathrm{m}^{3}$ and $11.2 \pm 4.1 \mathrm{mg} / \mathrm{m}^{3}$ respectively. The mean concentration of the particulate fractions generated at $180{ }^{\circ} \mathrm{C}$ and $150{ }^{\circ} \mathrm{C}$ were $42.4 \pm 13.0$ $\mathrm{mg} / \mathrm{m}^{3}$ and $28.0 \pm 3.5 \mathrm{mg} / \mathrm{m}^{3}$, respectively (Figure 13 ).

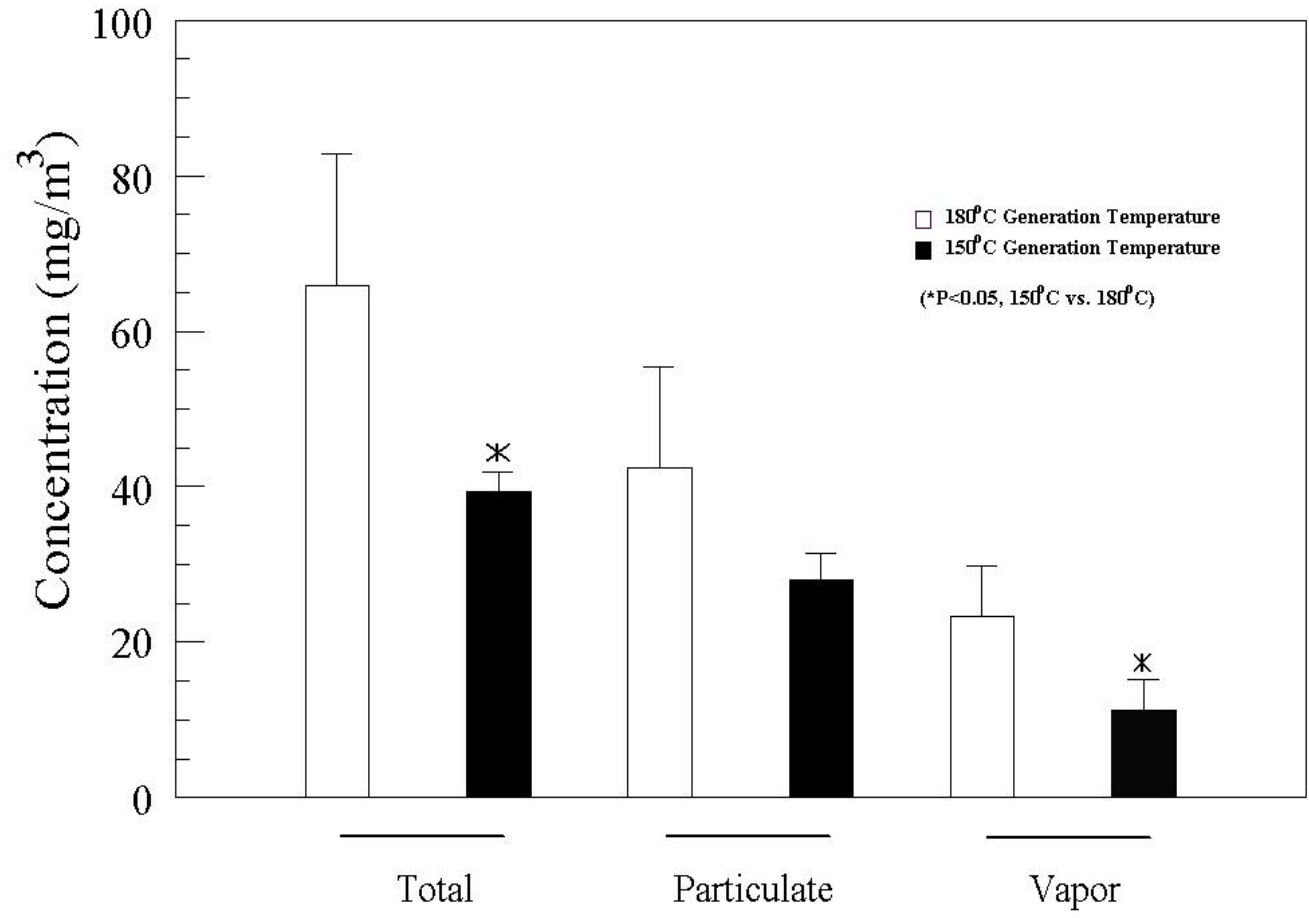

Figure 13- Exposure chamber air concentration of total asphalt fume and the particulate and vapor phases. Samples were collected on HEPA filters and XAD samplers, extracted into DCM and assayed by GC/MS-TIC mode, $n=4$, each. 


\subsection{Simulated Boiling Point Comparison}

A simulated boiling point profile was developed at both generation temperatures for the particulate and vapor fume fractions. The 5\% phenyl GC column separates compounds by boiling point allowing determination of boiling point by elution time relative to known standards. No significant qualitative shifts in the boiling point profiles were observed between $150{ }^{\circ} \mathrm{C}$ and $180^{\circ} \mathrm{C}$ for particulate or vapor fractions. Figure 14 contains representative chromatograms of the asphalt fume vapor and particulate fume. Figure 15 is an overlay of the $180{ }^{\circ} \mathrm{C}$ and $150{ }^{\circ} \mathrm{C}$ filter extract chromatograms. This figure shows how small the difference is between the two fumes. Figure 16 illustrates the same point using the XAD vapor extract. Figure 17 is a plot of the cumulative boiling point curves for both the particulate and vapor fractions of the fume generated at $150{ }^{\circ} \mathrm{C}$ and $180^{\circ} \mathrm{C}$. The mean mass boiling points (MMBPs) for the vapor component were 229 ${ }^{\circ} \mathrm{C}, 1.3 \sigma_{\mathrm{g}}$ and $235^{\circ} \mathrm{C}, 1.25 \sigma_{\mathrm{g}}$ for $180{ }^{\circ} \mathrm{C}$ and $150{ }^{\circ} \mathrm{C}$ generation temperatures, respectively. For the particulate fume fraction, the MMBPs for the $150{ }^{\circ} \mathrm{C}$ fume and 180 ${ }^{\circ} \mathrm{C}$ fume were $365^{\circ} \mathrm{C}, 1.17 \sigma_{\mathrm{g}}$ and $372{ }^{\circ} \mathrm{C}, 1.35 \sigma_{\mathrm{g}}$ respectively. A regression analysis of the boiling point profile data was performed for both $150{ }^{\circ} \mathrm{C}$ and $180{ }^{\circ} \mathrm{C}$ particulate and vapor fume components. The results indicated significant overlap within the $95 \%$ confidence intervals for both $150{ }^{\circ} \mathrm{C}$ and $180^{\circ} \mathrm{C}$ vapor and particulate lines. The slope $95 \%$ confidence interval $(95 \% \mathrm{CI})$ for $150{ }^{\circ} \mathrm{C}$ volatile compounds was 0.30 to 0.56 , the $95 \% \mathrm{CI}$ for $180{ }^{\circ} \mathrm{C}$ volatile compounds was 0.31 to 0.52 . The slope $95 \% \mathrm{CI}$ for $150{ }^{\circ} \mathrm{C}$ particulate compounds was 0.17 to 0.44 , the $95 \% \mathrm{CI}$ for $180{ }^{\circ} \mathrm{C}$ particulate compounds was also 0.17 to 0.44 . 


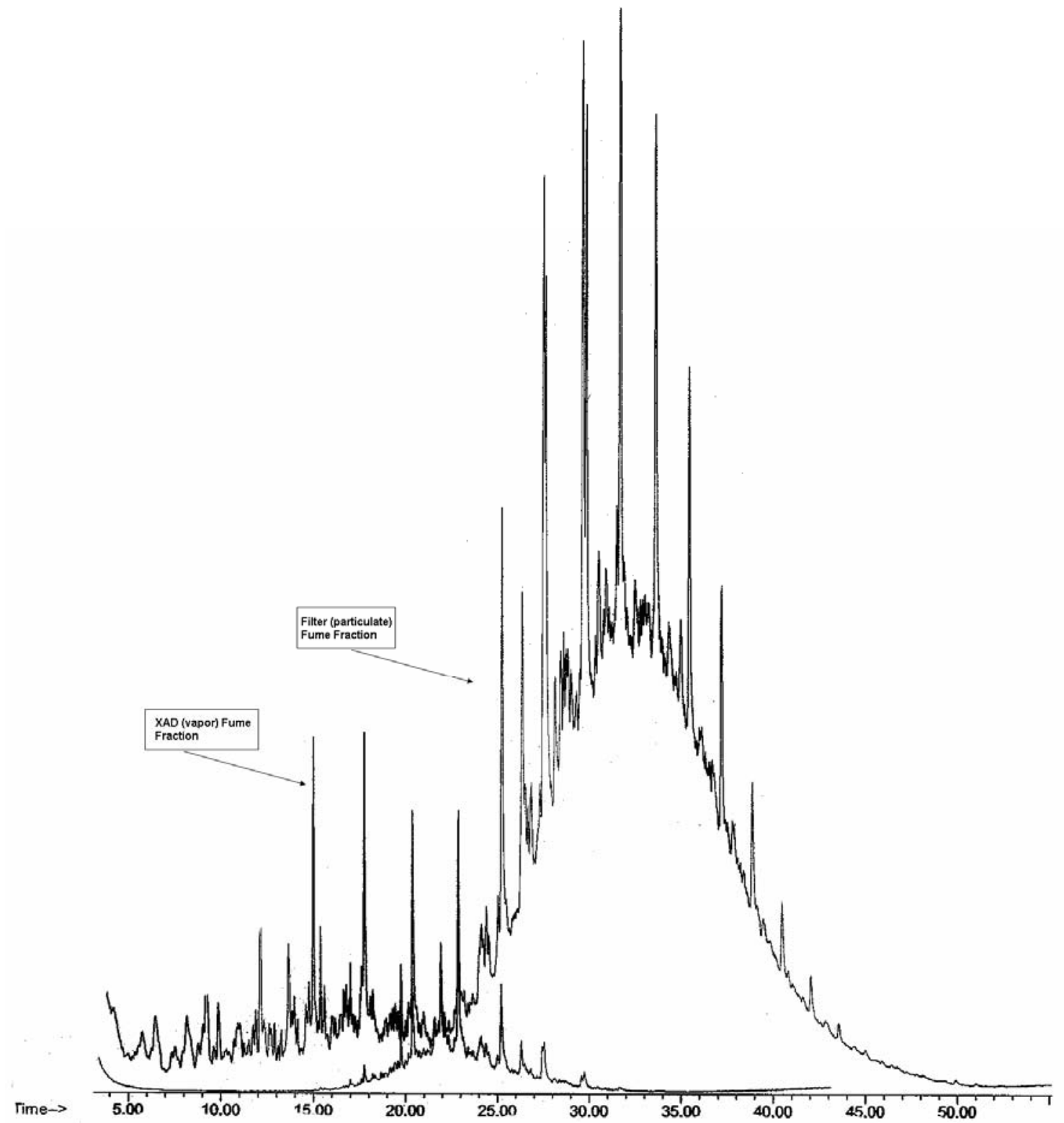

Figure 14- TIC overlay of XAD and filter extracts. 


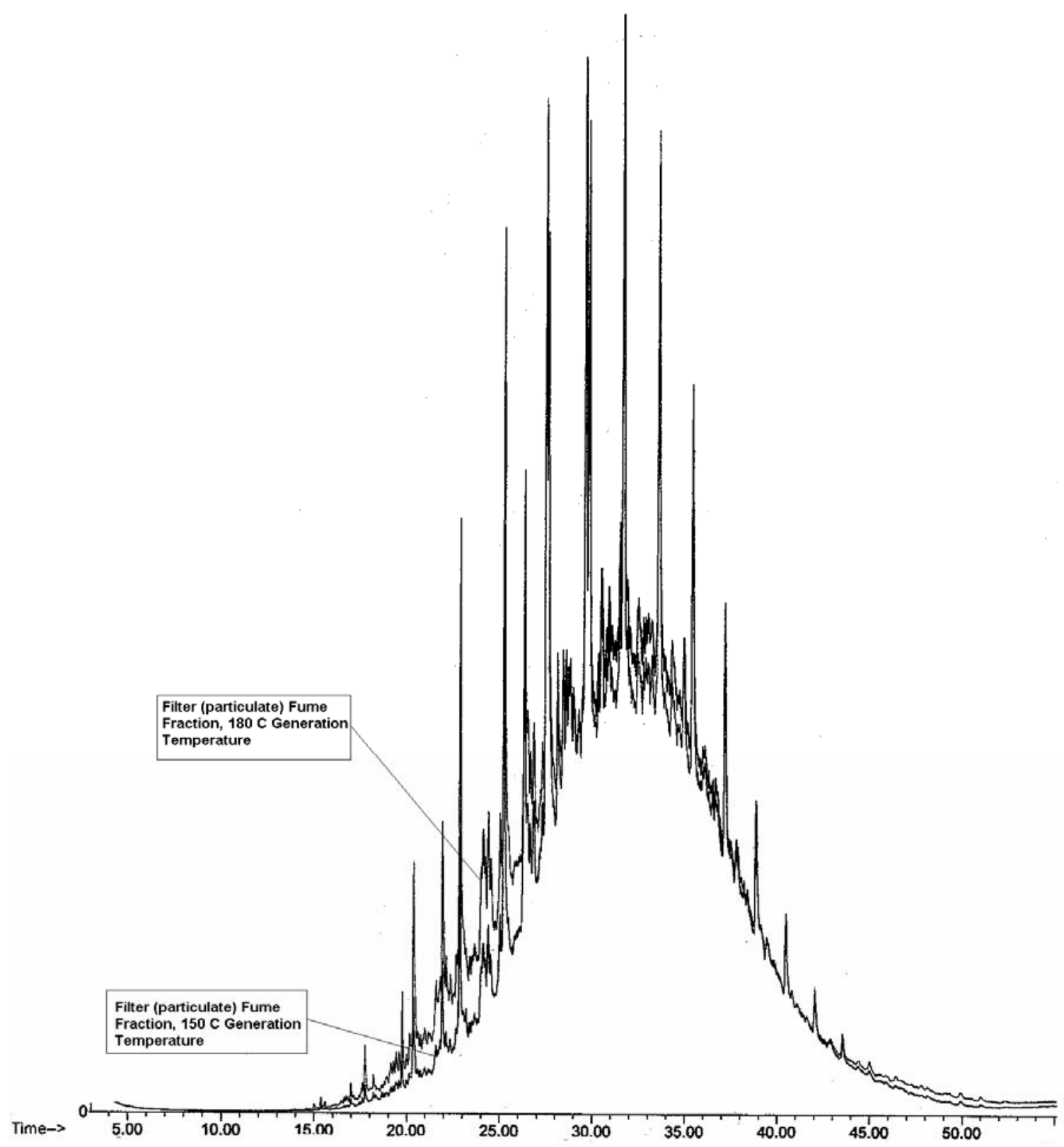

Figure 15- $180{ }^{\circ} \mathrm{C}$ and $150{ }^{\circ} \mathrm{C}$ filter (particulates) extracts overlaid. This shows a lack of qualititative change. 


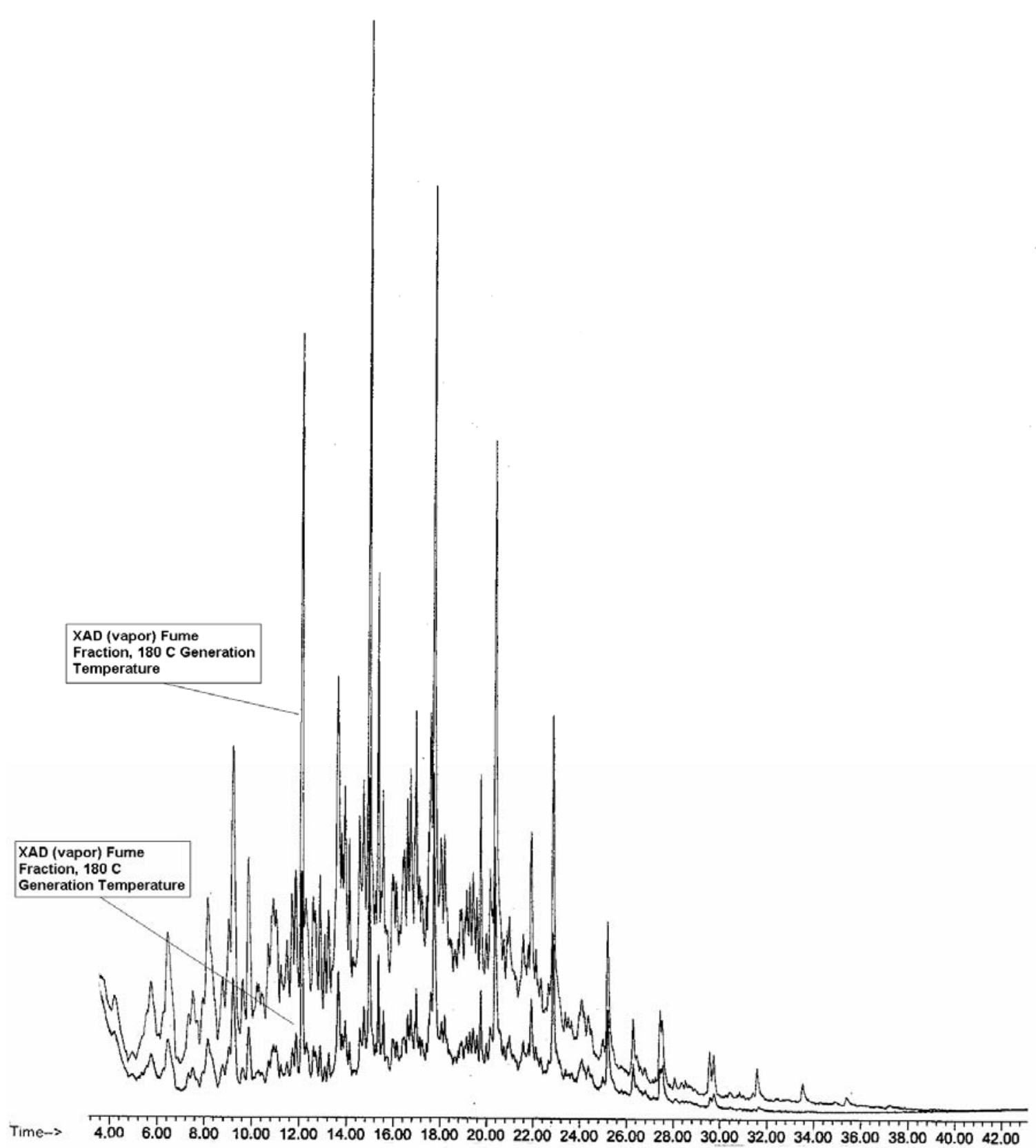

Figure 16- $180{ }^{\circ} \mathrm{C}$ and $150{ }^{\circ} \mathrm{C}$ XAD (vapor) extracts overlaid. This shows a lack of qualititative change. 


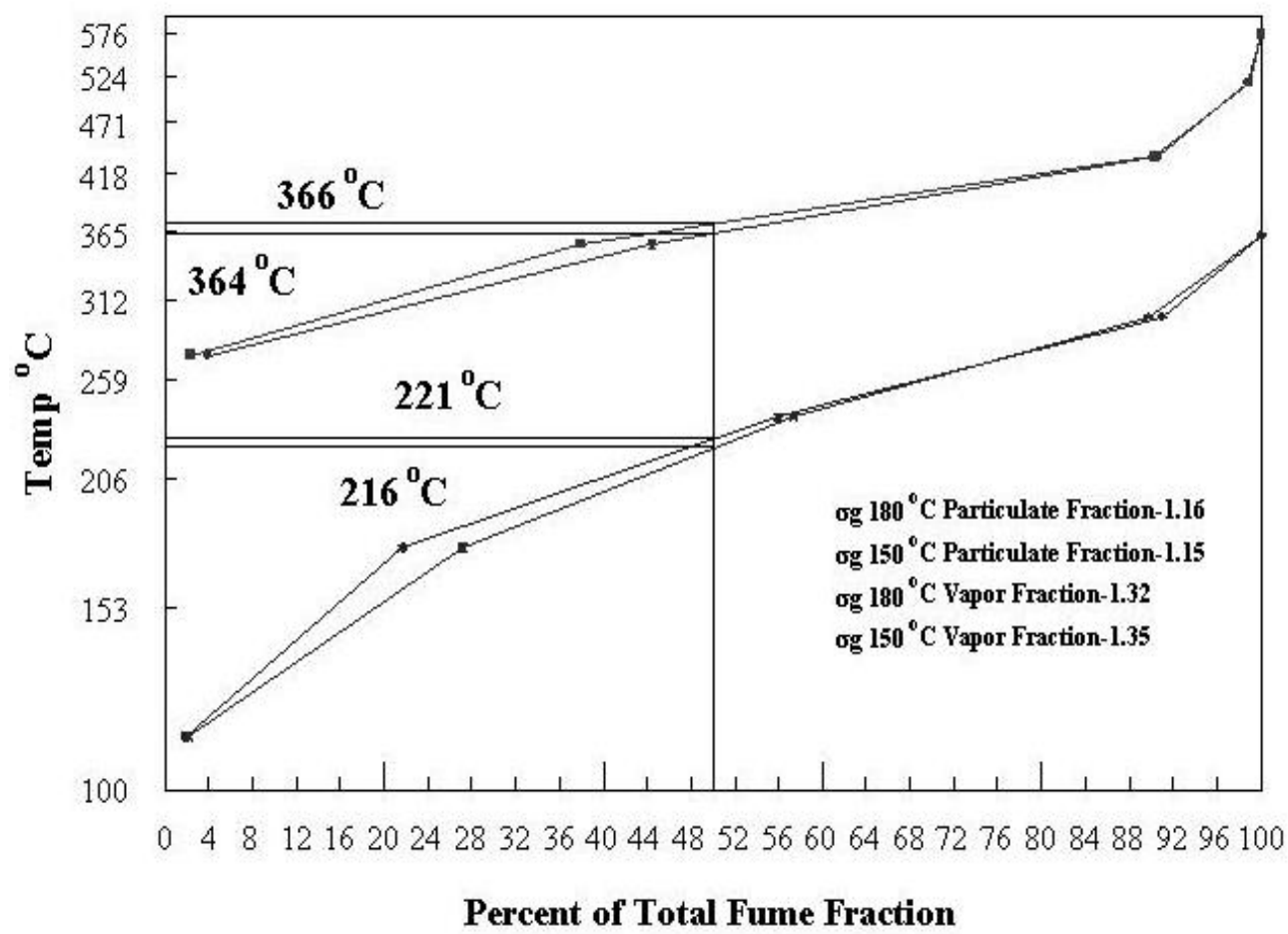

Figure 17- Simulated boiling point profile of $180{ }^{\circ} \mathrm{C}$ and $150{ }^{\circ} \mathrm{C}$ vapor and particulate fractions. Listed on the figure are the median cumulative boiling points, $366^{\circ} \mathrm{C}$ and $364{ }^{\circ} \mathrm{C}$ for the particulate fume fractions generated at $180{ }^{\circ} \mathrm{C}$ and $150{ }^{\circ} \mathrm{C}$ respectively. $221{ }^{\circ} \mathrm{C}$ and $216{ }^{\circ} \mathrm{C}$ for the vapor fume fraction generated at $180{ }^{\circ} \mathrm{C}$ and $150{ }^{\circ} \mathrm{C}$ respectively.

\subsection{Identification of PAH Compounds in Asphalt Fume Condensate}

HPLC fume fractions were collected by utilizing a $100 \%$ hexane hold to $100 \%$ DCM rapid gradient at a constant $1.5 \mathrm{ml} / \mathrm{min}$ flow rate. To simulate asphalt, kerosene and a PAH cocktail were mixed. Kerosene is a good surrogate for the aliphatic compounds that interfere with asphalt analysis, but like asphalt, kerosene also contains other compounds. The QTM mixture (Supelco \#47930-U) contains 16 PAH compounds which the EPA considers significant. After using various times, gradients, and flow rates the conditions for HPLC were chosen. The surrogate mixtures were also used to establish when the aliphatic compounds and the PAH compounds would elute from the column. This method established that the aliphatic compounds would elute between 25 and 40 minutes and the PAH compounds would start at 50 minutes. These times were 
established using a fluorescent detector set to an excitation wavelength of $254 \mathrm{~nm}$ and an emission wavelength of $400 \mathrm{~nm}$. Aliphatic compounds were detected using a photo diode array (PDA) scanning the UV range. The HPLC runs were started when the autosampler started its pre-injection method of washes. The surrogate mixture was also used to assess what losses occurred during processing and cleanup of the samples. The concern was that semi-volatile compounds such as naphthalene would be lost during the concentration step. Preliminary experiments established that there would be evaporative loss of naphthalene and that concentration and clean-up were not required for its quantification by GC-MS.

The recovery of PAH compounds from the HPLC cleanup method ranged from a low $8 \%$ for naphthalene (due to evaporative losses) to a high of $98 \%$ for indeno(1,2,3cd)pyrene, with the larger compounds $(4,5$, and 6 ring) having better recoveries than the smaller compounds ( 2 and 3 ring). The relative recoveries were accounted for by the use of appropriate internal standards. Naphthalene was quantified directly from the sample media extracts to prevent evaporative losses.

Figure 18 is a comparison of a representative fume sample total ion chromatogram (TIC) of the asphalt fume particulate crude DCM extract before and after the cleanup procedure to remove aliphatic compounds. The vast majority of the chemical composition of asphalt fume is aliphatic in nature. Electron impact ionization tends to fragment these compounds into many daughter ions that interfere with identification of the PAH compounds of interest. Phenanthrene is presented to demonstrate the need and utility of the cleanup procedure. It was observed, as demonstrated in Figure 19, that the $178 \mathrm{~m} / \mathrm{z}$ of interest was miniscule compared to the interfering ions. After the cleanup, not only was $178 \mathrm{~m} / \mathrm{z}$ clearly observable, the isotopic distribution for phenanthrene was discernable. It must be noted from the TIC that chromatographic resolution of the PAH compounds of interest was not sufficient to separate individual compounds, even after the extensive clean up. This precluded analyses by non-selective detectors such as the flame ionization detector. Using GC/MS in SIM mode resulted in the identification and quantification of seven PAH compounds of interest. The compounds identified were 
naphthalene, acenaphthene, fluorene, phenanthrene, fluoranthene, pyrene, and chrysene. Table IV summarizes the asphalt fume concentrations measured for these compounds. Naphthalene was the most abundant PAH identified. It must be noted that a small fraction of the total naphthalene may have also been present at trace levels in the particulate phase; however, interferences in crude extracts and evaporative losses during the cleanup procedure prevent its detection in the particulate phase. 


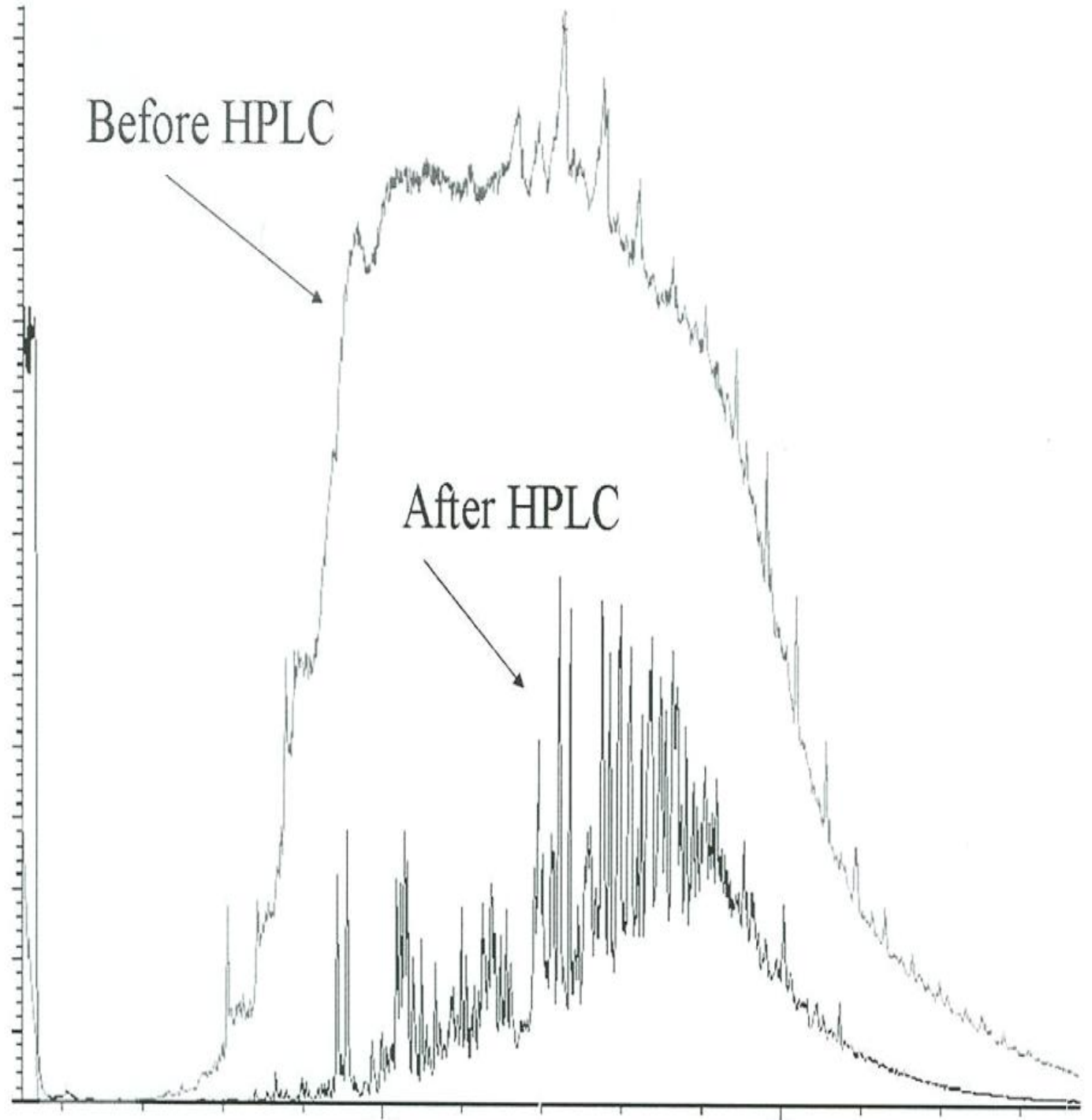

Figure 18- Representative total ion chromatogram of the same fume sample before and after the preparatory HPLC cleanup procedure to remove aliphatics. 


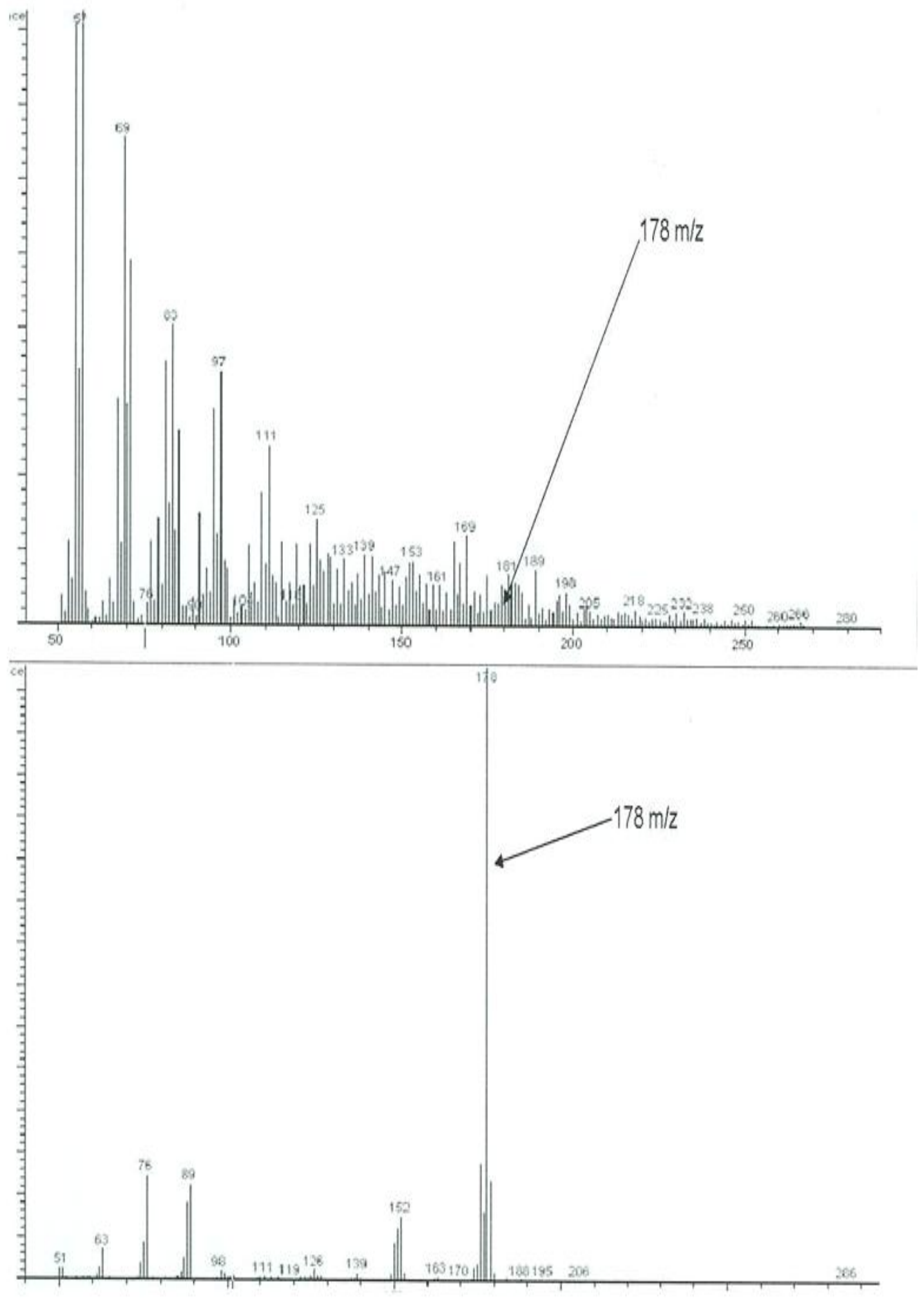

Figure 19- Representative EI-MS spectra are at 29.4 minutes. The top spectrum is the crude extract prior to HPLC cleanup, the bottom spectra is the same fume extract after the cleanup procedure. $178 \mathrm{~m} / \mathrm{z}$ is the molecular ion for phenanthrene 
Table IV. Summary of identified compounds and their concentrations at the150 ${ }^{\circ} \mathrm{C}$ and $180{ }^{\circ} \mathrm{C}$.

\begin{tabular}{|c|c|c|c|c|c|c|c|c|}
\hline \multicolumn{5}{|c|}{ Generation Temperature $=180^{\circ} \mathrm{C}$} & \multicolumn{3}{c|}{ Generation Temperature $=150^{\circ} \mathrm{C}$} \\
\hline PAH & $\begin{array}{c}\text { Vapor } \\
\mu \mathrm{g} / \mathrm{m}^{3}\end{array}$ & $\begin{array}{c}\text { Part. } \\
\mu \mathrm{g} / \mathrm{m}^{3}\end{array}$ & $\begin{array}{c}\text { Total } \\
\mu \mathrm{g} / \mathrm{m}^{3}\end{array}$ & $\begin{array}{c}\text { PPM } \\
\text { weight of } \\
\text { total } \\
\text { fume) }\end{array}$ & $\begin{array}{c}\text { Vapor } \\
\mu \mathrm{g} / \mathrm{m}^{3}\end{array}$ & $\begin{array}{c}\text { Part. } \\
\mu \mathrm{g} / \mathrm{m}^{3}\end{array}$ & $\begin{array}{c}\text { Total } \\
\mu \mathrm{g} / \mathrm{m}^{3}\end{array}$ & $\begin{array}{c}\text { weight of } \\
\text { total } \\
\text { fume) }\end{array}$ \\
\hline Nap. & $185.8 \pm 53.5$ & $\mathrm{ND}$ & $185.8 \pm 53.5$ & $2826 \pm 813.9$ & $146.3 \pm 12.8$ & $\mathrm{ND}$ & $146.3 \pm 12.8$ & $3726 \pm 326.3$ \\
\hline Acenap. & $1.89 \pm 2.7$ & $0.63 \pm 0.75$ & $2.52 \pm 2.7$ & $34.4 \pm 38.5$ & $2.4 \pm 1.2$ & ND & $2.4 \pm 1.2$ & $60.6 \pm 30.9$ \\
\hline Fluore. & $8.21 \pm 9.7$ & $2.63 \pm 0.33$ & $10.84 \pm 9.7$ & $165.0 \pm 151.3$ & $8.7 \pm 4.4$ & $1.67 \pm 0.29$ & $10.37 \pm 4.4$ & $264.5 \pm 182.8$ \\
\hline Phenan. & $13.4 \pm 13.7$ & $10.08 \pm 1.13$ & $23.48 \pm 13.7$ & $357.2 \pm 217.8$ & $20.0 \pm 28.5$ & $7.98 \pm 1.10$ & $27.98 \pm 28.5$ & $712.6 \pm 716.7$ \\
\hline Fluora. & ND & $0.29 \pm 0.39$ & $0.29 \pm 0.39$ & $7.8 \pm 8.4$ & ND & $1.02 \pm 0.31$ & $1.02 \pm 0.31$ & $6.2 \pm 9.5$ \\
\hline Pyrene. & $1.3 \pm 5.9$ & ND & $1.3 \pm 5.9$ & $84.9 \pm 86.6$ & $3.3 \pm 5.9$ & ND & $3.3 \pm 5.9$ & $212.3 \pm 302.2$ \\
\hline Chrys. & ND & $1.19 \pm 0.78$ & $1.19 \pm 0.78$ & $18.1 \pm 11.9$ & ND & $1.60 \pm 0.40$ & $1.60 \pm 0.40$ & $40.9 \pm 10.3$ \\
\hline
\end{tabular}

\subsection{Use of Fluorescent Techniques for the Identification and Quantification of PAH Compounds}

It was not possible using the described techniques to identify or quantify the class (the number of rings present) of PAH compounds in the asphalt fume samples. Further scrutiny using three-dimensional synchronous scanning fluorescence techniques failed to yield adequate separation to identify compounds by specific ring numbers. Figures 20-25

show some examples of the three-dimensional synchronous scanning fluorescence results. Scans were all run using the same instrument settings, however the software auto-scaled the scans. The scans have areas of specificity; naphthalene has specific peaks at four coordinate sets; $280 \mathrm{~nm}, 50 \mathrm{~nm} ; 300 \mathrm{~nm}, 30 \mathrm{~nm} ; 350 \mathrm{~nm}, 40 \mathrm{~nm}$; and $400 \mathrm{~nm}, 50 \mathrm{~nm}$. Specific areas can be seen in all the scans of pure compounds or simple mixtures. Areas of specificity were not discernable when scans were performed on the particulate, vapor, and PAH mixture. 


\section{Discussion}

Quantitative differences were observed in vapor fume fraction concentrations between the $180{ }^{\circ} \mathrm{C}$ and $150{ }^{\circ} \mathrm{C}$ generation temperatures. Crude asphalt, even from the same lot, is a non-homogenous mixture. This adds to the variability when examining both qualitative and quantitative differences. All specific PAH compounds identified in the $180{ }^{\circ} \mathrm{C}$ fume were also present in the $150{ }^{\circ} \mathrm{C}$ fume.

A simulated boiling point profile was developed for the particulate and vapor fume fractions. Again, there was no observable shift in boiling point curves in either fraction. Minor changes could be observed in areas of the curve; however, mean boiling points remained unchanged between generation temperatures. This suggests that fume composition differences noted in published reports generated during road paving operations adhering to industry standards $\left(150{ }^{\circ} \mathrm{C}\right.$ to $\left.180{ }^{\circ} \mathrm{C}\right)$ are probably not attributable to differences in application temperature.

Prior to running the extracts through the clean-up procedure, it was not possible to identify specific PAH compounds from the filter extracts. The low abundance PAH ions were overwhelmed by the more abundant aliphatic compound ions in the mass spectrum. Using selected ion monitoring resulted in awry specific ion ratios compared to the standards, preventing unequivocal identification and quantification of individual PAHs. When using the present HPLC preparatory (cleanup) method prior to GC/MS-SIM analysis, the $\mathrm{m} / \mathrm{z}$ and isotopic distribution were prominent, allowing for identification and quantification of the PAH compounds. Seven specific PAH compounds were identified with high confidence in the fume. The compounds identified were two, three, and four ring species. This identification was based on relative retention times (RRTs) and isotopic distribution around the molecular ion peak. RRTs were acceptable if they were within one standard deviation of the mean RRTs from the standards. Two additional compounds, benzo(a)anthracene and benzo(b)fluoranthene, may have been present, however, they were at too low a concentration in the fume to confirm their identity. 
Using the National Institute of Standards and Technology library, several substituted compounds were also identified including methyl, dimethyl, and trimethyl naphthalenes; ethyl naphthalenes; methyl and dimethyl fluorenes; methyl anthracenes; methyl phenanthrene; and methyl anthracene. These matches had greater than $90 \%$ quality; however, the specific compounds (i.e. position of the methyl groups) were not delineated against standard reference materials. The fume concentrations generated for these experiments were actually much higher than that reported from road paving operations ${ }^{(44)}$. This allowed for highly concentrated samples for analyses.

Many reports have used less selective techniques such as HPLC fluorescence, GC/MS-SIM based on one ion and GC-flame ionization detectors to identify and measure specific compounds. In this study, monitoring just a single ion and retention time from crude extracts would have indicated the presence 15 of the 16 PAH compounds investigated with the only exception being 2-bromonaphthylene.

In a highly complex mixture with hundreds to thousands of interfering compounds, care should be taken to ensure positive identification. Even when monitoring three $\mathrm{m} / \mathrm{z}$ at given retention times, these $\mathrm{m} / \mathrm{z}$ were present in some cases, however upon further scrutiny by using isotopic distributions it became clear that these ions could not be fully attributed to the compounds of interest. Benzo(a)pyrene has been identified in the past using single-ion-monitoring and retention times from asphalt fume extracts. Because of the great variability in asphalt, it was possible that the benzo(a)pyrene was present, but critical assessment of appropriate methodology is often difficult from the published literature. In our studies, after the preparatory HPLC method, the $\mathrm{B}(\mathrm{a}) \mathrm{P} \mathrm{m} / \mathrm{z}$ were not present above background noise. These results underscore the difficulty associated with assessment of complex chemical exposures, and the requirement of multiple, selective analytical procedures to properly characterize general and specific chemical characteristics of such environments.

The material used in the HPLC column was available in SPE cartridges. The solvent gradient used would easily lend itself to an SPE method and would have the 
advantage of multiple samples at a given time. After evaluating many PDVB SPE methods however, the analyte recoveries were not adequate for this purpose. The reason(s) for the drastic difference in analyte retention between the low pressure SPE method and the high pressure HPLC purification were not determined in the present study.

There are numerous sampling, extraction, cleanup, and analysis methods available for identification and quantification of trace PAH compounds. Such methods vary with respect to complexity, utility, and validity for extremely complex mixtures. GC-MS in the absence of prior extensive sample cleanup is plagued with interferences. Reverse or normal phase HPLC-fluorescence detection lacks both chromatographic resolution and detection specificity for this application. Solid-phase extraction techniques employed for cleanup in the procedure for total PAH analyses was examined ${ }^{(15)}$, but were not adequate for specific chemical analyses by GC/MS. Addition of a liquid/liquid partitioning step between hexane and DMSO provided adequate clean-up, but poor and variable recoveries of individual PAH compounds (data not shown). The DMSO solvent prevented further sample concentration in addition to being a poor GC/MS solvent.

The methods developed for this report worked well and allowed for confident identification and quantification of specific PAH compounds, characterization of the boiling point profile of asphalt fume vapor and particulate fractions, and establishing correction factors for standards previously used for quantification of PAH from complex mixtures. The cleanup method allowed for collection of a single fraction, which represents a major improvement of collecting numerous fractions required by normal phase preparatory HPLC sample cleanup procedures. A limiting factor to the analyses provided was the sensitivity and specificity of the MS detector. The GC/MS system is one that is widely used and available in most environmental/industrial hygiene chemistry laboratories. The GC/MS in SIM mode worked well using strict criteria to identify PAH compounds with high confidence, following the preparatory HPLC cleanup to remove the abundant interferences.

In conclusion, it can be said that previous studies, based on the data presented in this study, may be overestimating the concentrations of PAH compounds present in 
asphalt fume from paving operations. The boiling point profile of fumes generated show no qualitative difference across industry accepted paving temperature ranges. This data also indicated that fluorescence techniques may have little value in accurately identifying and quantifying compounds based on ring numbers or specific compounds based on standards in complex mixtures. 


\section{References}

1. Asphalt Institute:Report to OSHA and NIOSH: Status of Asphalt Industry Steering Committee research program on the health effects of asphalt fumes and recommendation for a worker health standard.(1990)

2. Asphalt Institute:United Sates asphalt usage report.(1989)

3. Jarvholm, B., Nordstrom, G., Levin, J. O., Wahlstrom, J., Ostman, C., and Bergendahl, C.:Exposure to polycyclic aromatic hydrocarbons and genotoxic effects on nonsmoking Swedish road pavement workers.Scand.J.Work Environ.Health25:131-136-(1999)

4. Toraason, M, Hayden, C, Marlow, D., Rinehart, R., Mathias, P., Werren, D., DeBord, D. G., and Reid, T. M.:DNA strand breaks, oxidative damage, and $1-\mathrm{OH}$ pyrene in roofers with coal-tar pitch dust and/or aspahlt fume exposure.Int.Arch.Occup.Environ.Health74:396-404(2001)

5. King, R. W., Puzinauskas, V. P., and Holdsworth, C. E.:Asphalt Composition and health effects: A critical review.Technical Report: American Petroleum Institute:1-11(1984)

6. American Society for Testing and Materials:Terms Relating to Materials for Roads and Pavements, ASTM Designation D8. (1976)

7. R.J.Forbes:Bitumen and Petroleum in Antiquity. (1936)

8. Process Association:Asphalt Paving Technology. 43A: (1974)

9. U.S.Department of Commerce:Statistical Abstracts of the United States. 716(1961)

10. Gamble, J. F., Nicolich, M. J., Barone, N. J, and Vincent, W. J:Exposure-response of asphalt fumes with changes in pulmonary function and symptoms.Scand.J.Work Environ.Health25:186-206(1999)

11. James Melius:Asphalt - A Continuing Challenge. American Journal of Industrial Medicine43:235-236 (2003)

12. J.G.Speit:The Chemistry and Technology of Petrolium. (1991)

13. J.G.Speit:Fuel Science and Technology Handbook. (1990)

14. National Institute for Occupational Safety and Health:Publication Number 2001110. (2001) 
15. National Institute for Occupational Safety and Health:Polynuclear aromatic hydrocarbons: Method 5506. NIOSH Manual of Analytical Methods4th Ed.: (1994)

16. Patra, D. and Mishra, A. K.:Study of diesel fuel contamination by excitation emission maxtrix spectral subtraction fluorescence.

Anal.Chim.Acta.454:209-215 (2002)

17. Guiteras, J, Beltran, J. L., and Ferrer, R.:Quantitative multicomponent analysis of polycyclic aromatic hydrocarbons in water samples. Anal.Chim.Acta.361:233-240 (1998)

18. Alf Bjorseth:Physical and Chemical Properties of PAHs. Handbook of Polycyclic Aromatic Hydrocarbons. 1-25 (1983)

19. Phillips, D. H.:FIfty years of benzo[a]pyrene. Nature303:468-472 (1983)

20. International Agency for Research on Cancer:Monographs on the evaluation of carcinogenic risks to humans. 1:49- (1990)

21. Kathryn Martin Remington, Samuel E.Bennett, and Constance M.Harris:Highly Mutagenic Bypass Synthesis by T7 RNA Polymerase of Site-Specific Benzo[a]pyrene Diol Epoxide-Adducted Template DNA. Journal of Biological Inorganic Chemistry273:13170-13176 (1998)

22. Fang, J. L., Beland, F. A., Doerge, D. R., Wiener, D., Guillemette, C., Marques, M. M., and Lazarus, P.:Characterization of benzo(a)pyrene-trans-7,8dihydrodiol glucuronidation by human tissue microsomes and overexpressed UDP-glucuronosyltransferase enzymes.Cancer Res.62:1978-1986(4-1-2002)

23. Lee, M, M.V.Novotny, and K.D.Bartle:Analytical chemistry of polycyclic aromatic hydrocarbons. (1981)

24. Nishioka, M., H.-Y.Chang, and M.Lee:Structural characteristics of polycyclic aromatic hydrocarbon isomers in coal tars and combustion products. Environ.Sci.Technol.20:1023-1027 (1986)

25. Wang, Z., M.Fingas, Y. Y. Shu, L.Sigouin, M.Landriault, and P.Lambert:Quantitative characterization of PAHs in burn residue and soot samples and differentiation of pyrogenic PAHs from petrogenic PAHs- the 1994 mobile burn study. Environ.Sci.Technol.33:3100-3109 (1999)

26. The Asphalt Institute:Asphalt Hot-Mix Emmision Study, Research Report RR-75-1. (1975) 
27. Reinke G, Mark Swanson, Dennis Paustenbach, and John Beach:Chemical and Mutagenic Properties of Asphalt Fume Condensates Generated Under Laboratory and Field Conditions. Mutation Research/Genetic Toxicology and Environmental Mutagenesis469:41-50 (2000)

28. Watts, R. R., Wallingford, K. M., Williams, R. W., House, D. E., and Lewtas, J.:Airborne exposures to $\mathrm{PAH}$ and $\mathrm{PM}_{2.5}$ particles for road paving workers applying conventional asphalt and crumb rubber modified asphalt.J.Expos.Anal.Environ.Epidemiol.9:213-229(1998)

29. Burstyn, Igor, Kromhout, Hans, Kauppinen, Timo, Heikkila, Pirjo, and Boffetta, Paolo:Statistical Modelling of the Determinants of Historical Exposure to Bitumen and Polycyclic Aromatic Hydrocarbons among Paving Workers. The Annals of Occupational Hygiene44:43-56(2000)

30. Bonnet, P., Binet, S., Brandt, H., Kriech, A. J., Lafontaine, M., Nunge, H., Morele, Y., de Groot, P., Wissel, H., and Castegnaro, M.:Inhalation study on exposure to bitumen fumes: Part 1: Development and validation of the equipment.The Annals of Occupational Hygiene44:15-29(2000)

31. S.Monarca and R.Pasquini, S. G. Scassellati A. Savino F. A. Bauleo G. Angeli:Environmental Monitoring of Mutagenic and Carcinogenic Hazards During Road Paving Operations with Bitumens. Int.Arch.Occup.Environ.Health59:393-402 (1987)

32. Cerniglia, C E.:Biodegredation fo polycyclic aromatic hydrocarbons. Biodegredation3:351-368 (1992)

33. Toxicology and carcinogenesis studies of naphthalene (cas no. 91-20-3) in F344/N rats (inhalation studies).Natl.Toxicol.Program.Tech.Rep.Ser.1-173(2000)

34. Toxicology and Carcinogenesis Studies of Naphthalene (CAS No. 91-20-3) in B6C3F1 Mice (Inhalations tudies). Natl. Toxicol. Program. Tech. Rep. Ser.410:1-172(1992)

35. Qian, H.-W., Ong, T., and Whong, W.-Z.:Induction of micronuclei in cultured mammalian cells by fume condensates of roofing asphalt. Am. J. Ind. Med. 29:554-559(1998)

36. Ma, J. Y., Barger, M. W., Kriech, A. J., and Castranova, V.:Effects of asphalt fume condensate exposure on acute pulmonary responses.Arch.Toxicol.74:452459(2000)

37. Sivak, A., Niemeier, R., Lynch, D., Beltis, K., Simon, S., Salomon, R., Latta, R., Belinky, B., Menzies, K., and Lunsford, A.:Skin carcinogenicity of condensed asphalt roofing fumes and their fractions following dermal application to mice.Cancer Letters117:113-123(7-15-1997) 
38. Ma, J. Y., Rengasamy, A., Frazer, D., Barger, M. W., Hubbs, A. F., Battelli, L., Tomblyn, S., Stone, S., and Castranova, V.:Inhalation exposure of rats to asphalt fumes generated at paving temperatures alters pulmonary xenobiotic metabolism pathways without lung injury.Environ.Health Perspect.111:1215-1221(2003)

39. Antonini, J. M., Roberts, J. R., Taylor, M. D., Yin, X., Stone, S., Moseley, A., Ma, J. K., Frazer, D. G., Castranova, V., and Ma, J. Y.:Effect of asphalt fume inhalation exposure at simulated road paving conditions prior to bacterial infection on lung defense responses in rats.Inhal.Toxicol.15:13471368(2003)

40. Fuchs, J., Hengstler, J. G., Boettler, G., and Oesch, F:Primary DNA damage in peripheral mono-nuclear blood cells of workers exposed to bitumen-based products.Int.Arch.Occup.Environ.Health68:141-146(1996)

41. Norseth, T, Waaje, J, and ale, I:Acute effects and exposure to organic compounds in road maintenance workers exposed to asphalt.Am J Ind Med.20:737744(1991)

42. Maizlish, N, Beaumont, J, and Singleton, J:Mortality among California highway workers.Am J Ind Med.13:363-379(1988)

43. Jiao, Kaisheng and Lafleur, Arthur L.:Improved detection of polycyclic aromatic compounds in complex mixtures by liquid chromatographic fractionation on poly(divinylbenzene) prior to gas chromatography-mass spectrometry: Application to the analysis of diesel particulates.Journal of Chromatography A791:203-211(12-12-1997)

44. Apicella, B., Ciajolo, A., and Tregrossi, A.:Fluorescence spectroscopy of complex aromatic mixtures.Anal.Chem.76:2138-2143(4-1-2004)

45. Heikkila, P., Riala, R., Hameila, M., Nykyri, E., and Pfaffli, P.:Occupational exposure to bitumen during road paving.AIHA.J.(Fairfax., Va.)63:156$165(2002)$ 
Appendix I. Standard Curves Used for Quantification of Filter Extracts 

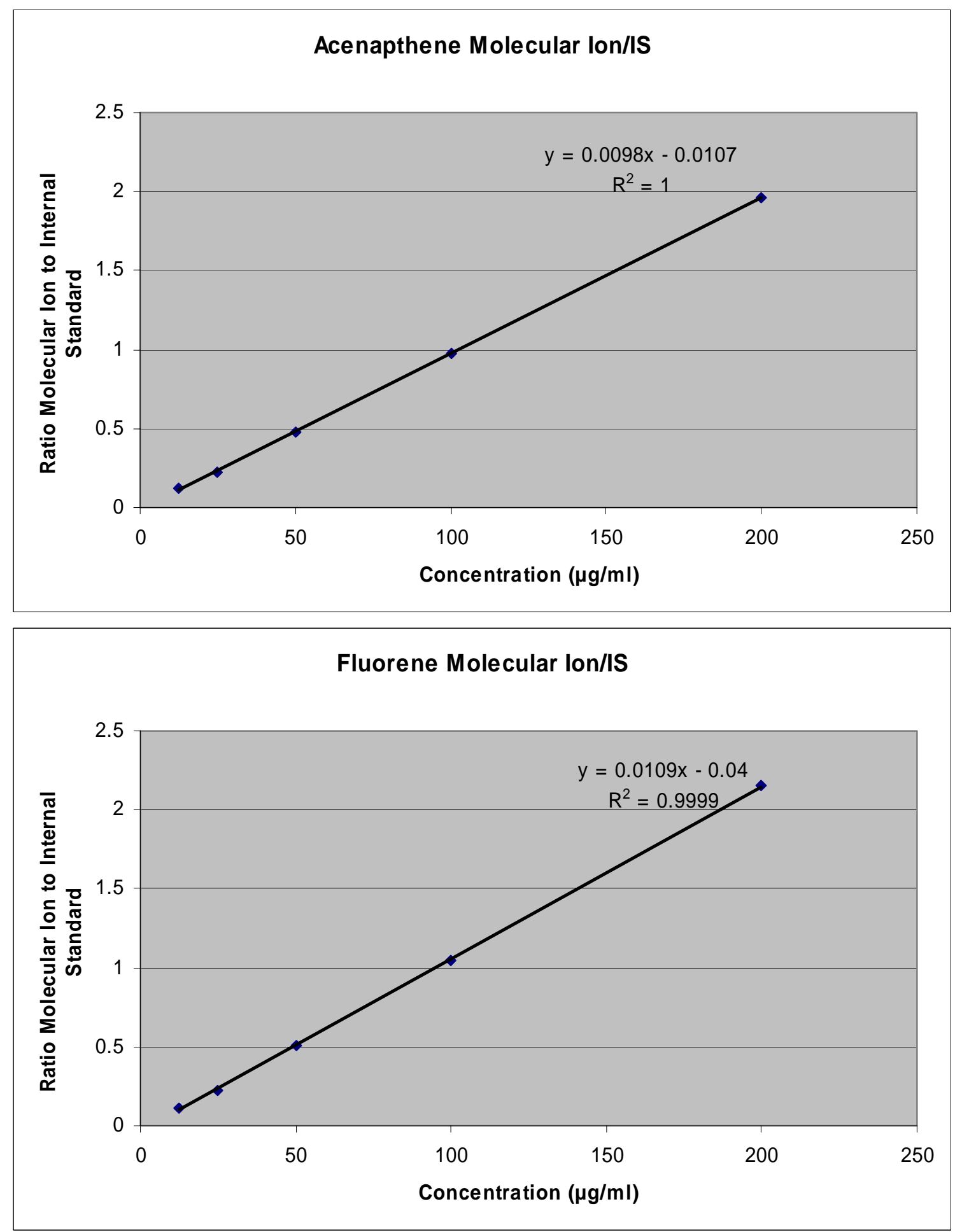

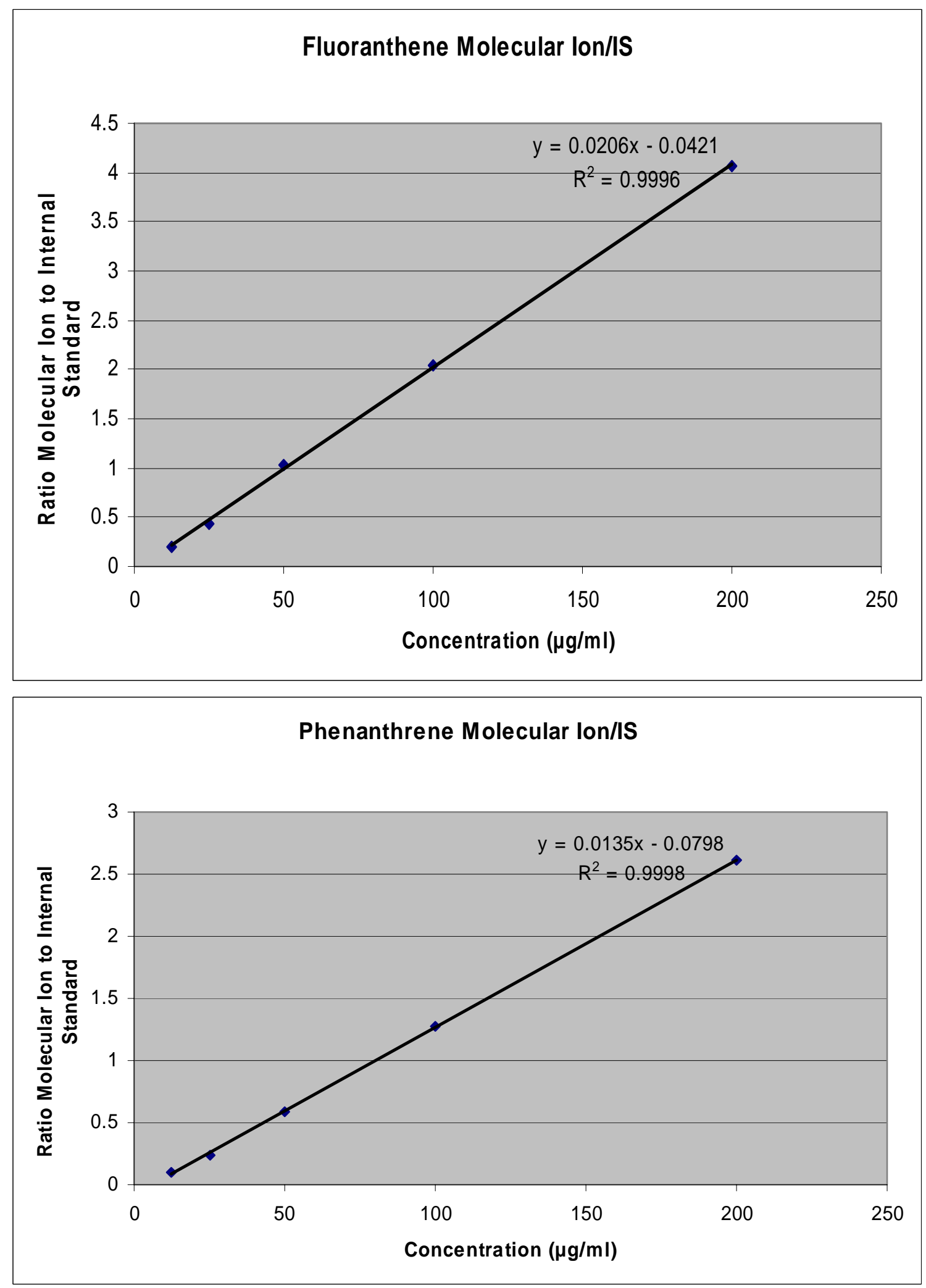


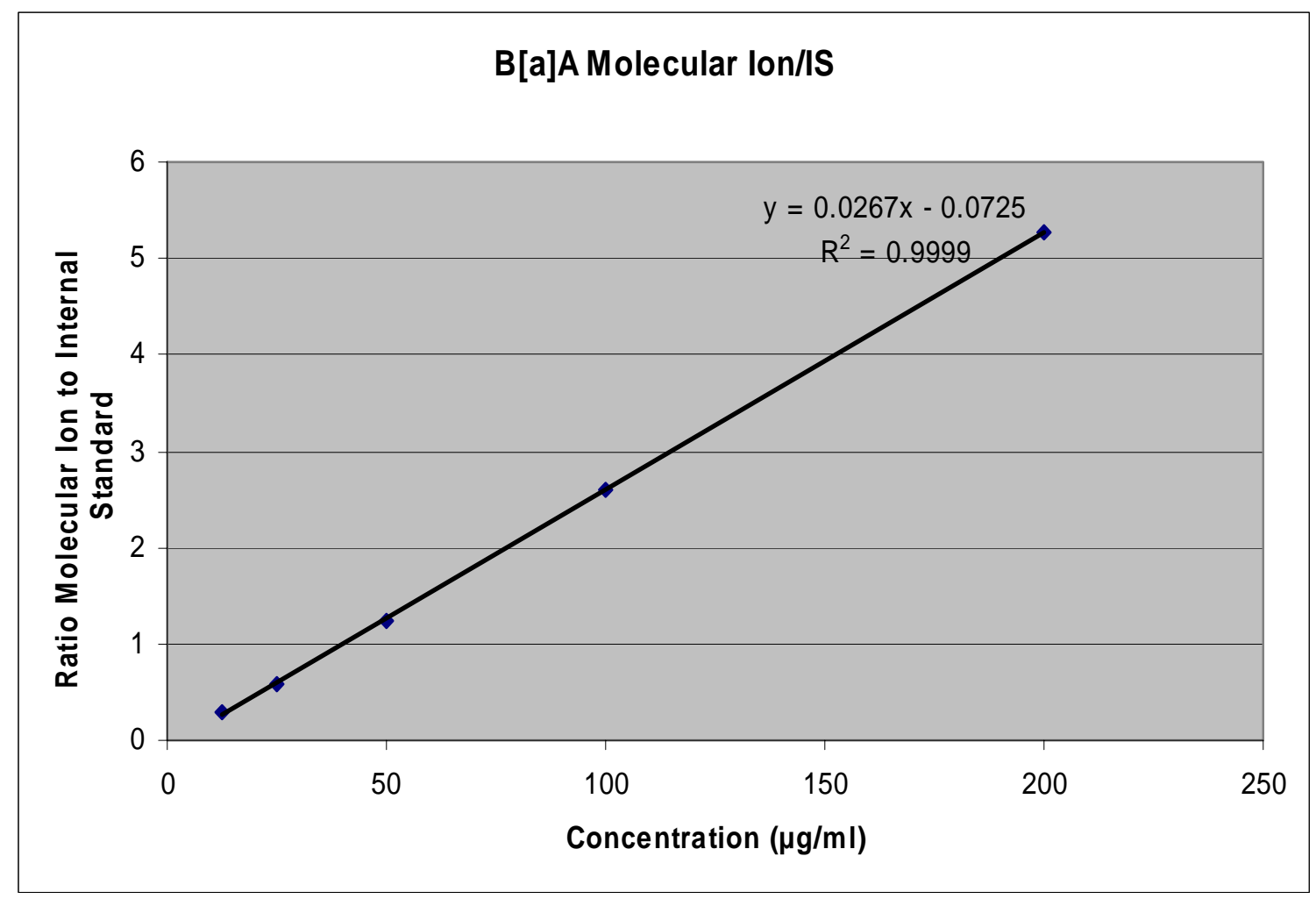

Standard Curve Used for the Quantification of XAD Naphthalene

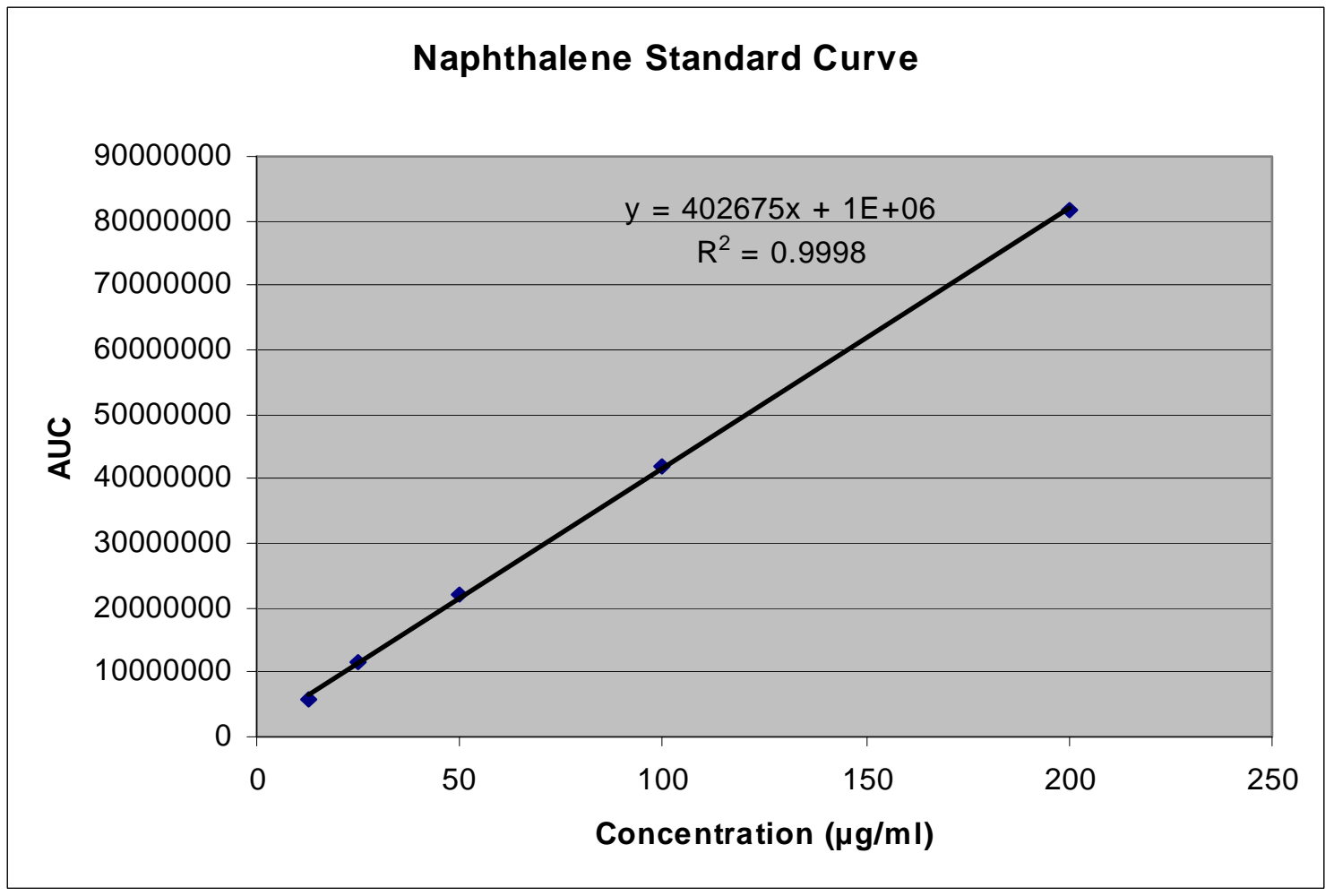


Standard Curves Used for XAD Extract Quantification other than naphthalene
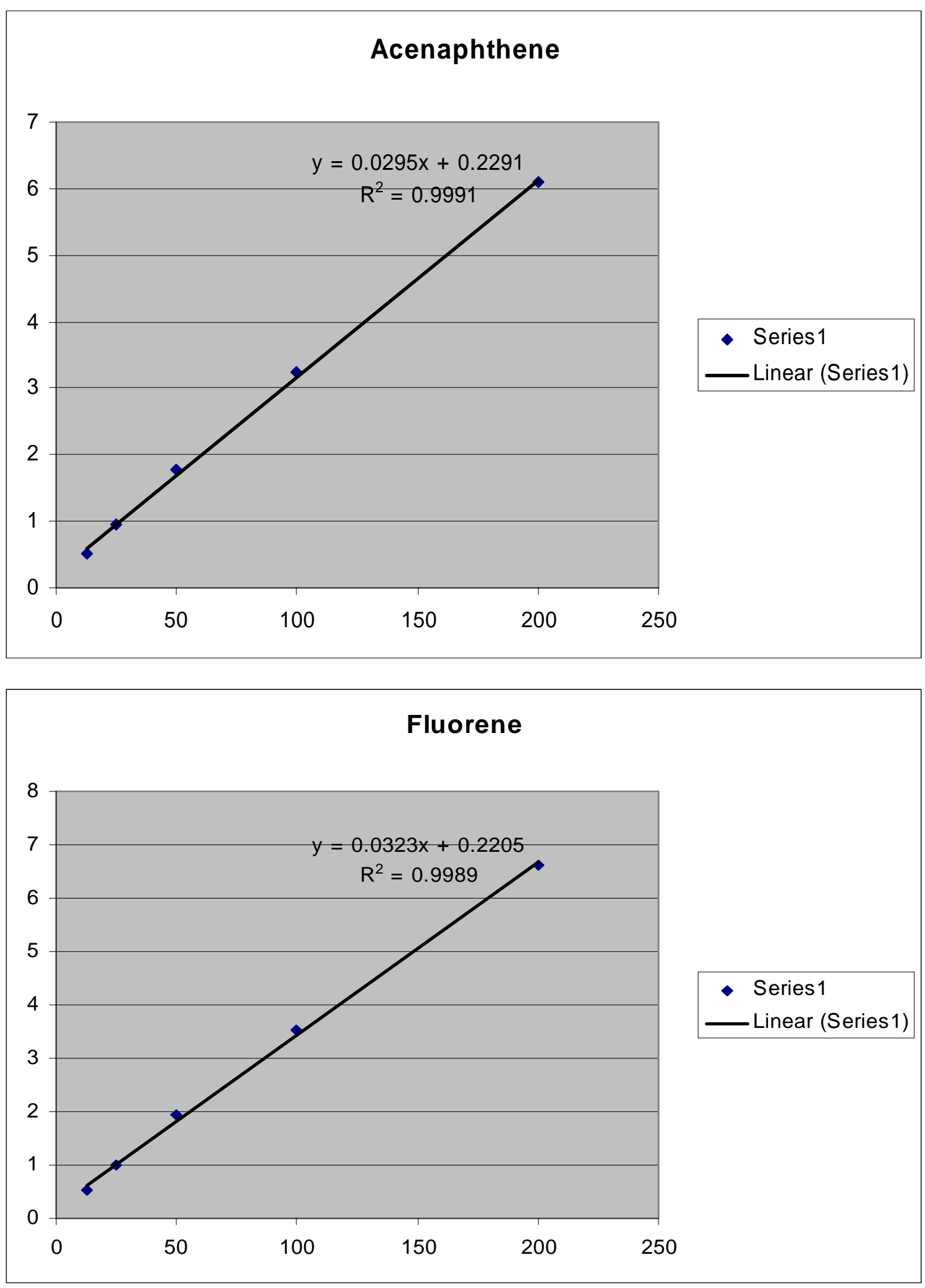

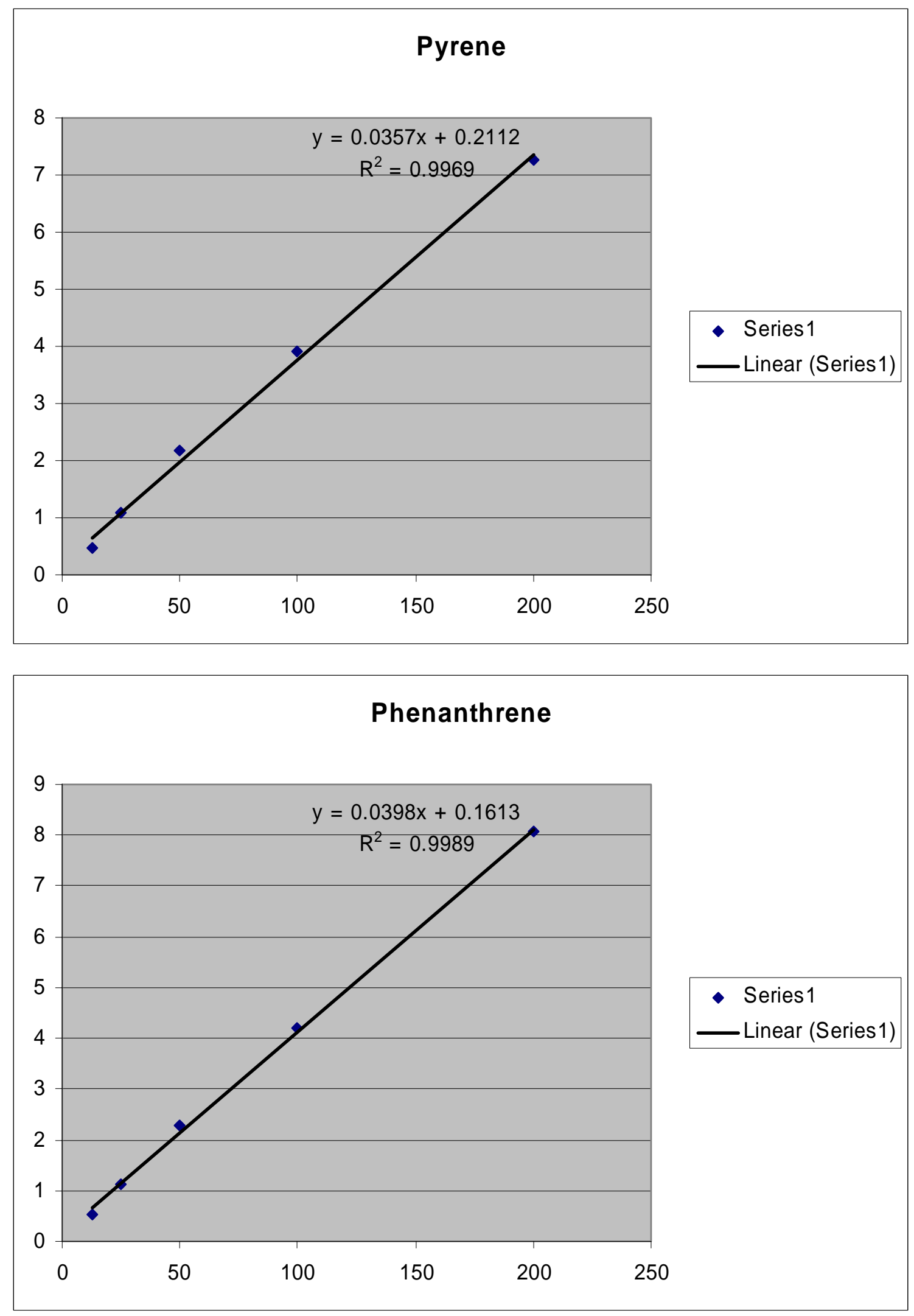


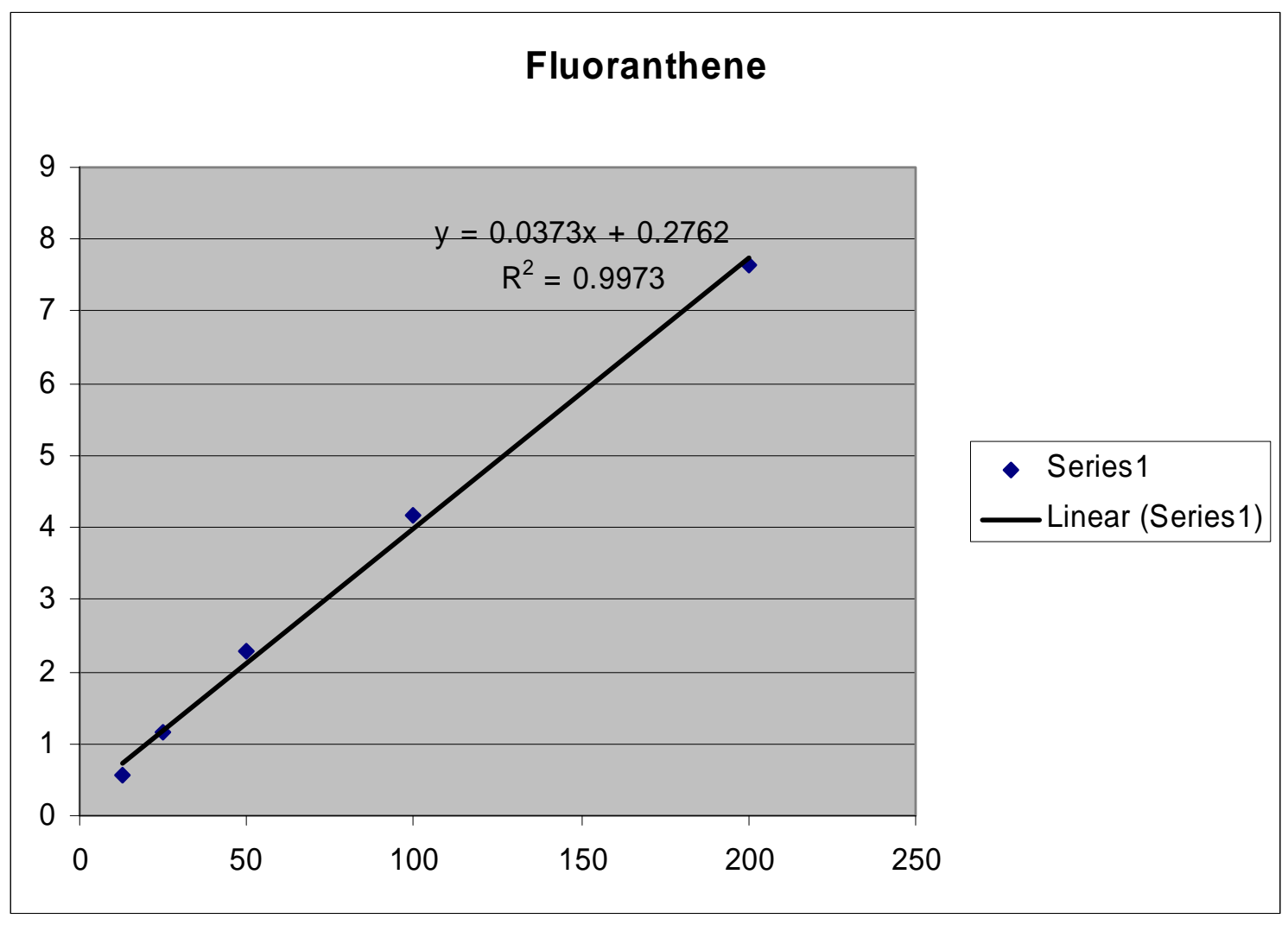




\section{Appendix II. Quality Control}

All instrumentation was calibrated with appropriate individual standards and mixes, these results were documented in a lab record. The gas chromatogram with mass spectrometer(GC/MS) was tuned using an autotune sequence built into the software. The autotune was performed for maximum sensitivity once a month and results were printed and logged in the instrument logbook. The instrument was calibrated using a PAH cocktail containing sixteen components, as previously described. Media blanks were prepared and analyzed to ensure there would be little or no contribution from the filter material and adsorbent material used. Blank solvent was also run to ensure no cross-over contamination between samples was present that would interfere with analyses. Three sets of standards were prepared with concentrations in the range of $200 \mathrm{ug} / \mathrm{ml}$ to 12.5 $\mathrm{ug} / \mathrm{ml}$. The instrument is equipped with an autosampler for consistent sample introduction onto the analytical column. A complete set of standards were placed at the start of the run, a second set was randomly dispersed through the run, and a third complete set was placed after the run. The mean of these three sets was used in the establishment of a quantitative standard curve and each was evaluated to ensure uniform analyese throughout each set of samples. There were four internal standards added to each standard and sample to account for constant losses due to the preparation and analysis procedures. An internal standard is a compound not found in the sample of interest, but has physical chemical similarities to the compounds to be accessed. Specific isotopes of several PAHs were used for this study as described previously. The final step in establishing standard curves for quantification was to calculate a ratio between the molecular ion of an individual compound in the PAH cocktail and the molecular ion of the appropriate internal standard. These ratios were then plotted against concentration. The ratios negate variability due to sample preparation and analyses. An example of the construction of the standard curve can be seen below in Table AIIl. 


\begin{tabular}{|ccc|}
\hline Table All1 & & \\
\hline Fluoranthene & $\begin{array}{c}\text { Molecular Ion } \\
\text { AUC }\end{array}$ & $\begin{array}{c}\text { Molecular Ion S. Mean/Molecular Ion IS } \\
\text { Concentration }\end{array}$ \\
ug/ml & $\mathbf{2 0 2}$ & \\
\hline 200 & 38453079 & 4.064738327 \\
100 & 19341989 & 2.04457292 \\
50 & 9729128 & 1.028431546 \\
25 & 4120558 & 0.435569543 \\
12.5 & 1948672 & 0.205987192 \\
& & \\
& Molecular lon & \\
Internal Standard & Mean & \\
Chrysene d10 & 9460161 & \\
\hline
\end{tabular}

Standards were used to establish an average elution time in the preparatory HPLC clean-up method. Since the concern was the class of chemical eluting and not the individual compound the mixture was run several times to find the mean elution time based on a fluorescent peak. Prior to clean-up runs the mixture was injected to establish that the fluorescent detector was working and no major shifts in elution time had occurred. The PAH cocktail was also run after the procedure. Internal standards were introduced prior to this step to negate any recovery varability. 


\section{Appendix III. HPLC Information}

The system was a GBC LC1150 pump, a Schimadzu RF-551 fluorescence detector, GBC LC5000 photo diode array, GBC LC1650 autosampler, and a GBC LC1460 degasser. The system was controlled using WinChrome V1.32 chromatographic software. 
Appendix IV. Gas Chromatograph and Mass Spectrometer (GC/MS) Information

The GC/MS system used was an Agilent 5890 series II plus GC coupled to an

Agilent 5972 MS detector. The system was controlled by Enhanced Chemstation,

V.B.01.00. 


\section{Appendix V. Sixteen PAH Compounds Included in the QTM Cocktail}<smiles>c1ccc2ccccc2c1</smiles>

Naphthalene<smiles>C1=Cc2cccc3cccc1c23</smiles>

Acenaphthylene

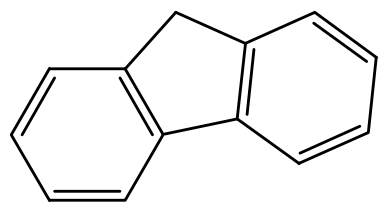

Fluorene<smiles>c1ccc2c(c1)-c1cccc3cccc-2c13</smiles>

Fluoranthene

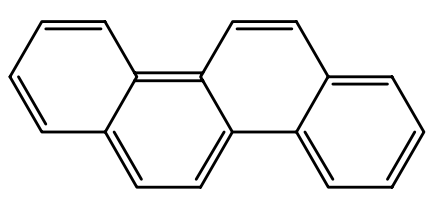

Chrysene<smiles></smiles>

Benzo[ghi]perylene<smiles>Brc1ccc2ccccc2c1</smiles>

2-Bromonaphthalene

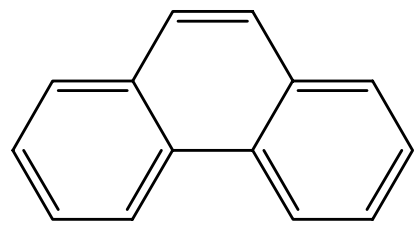

Phenanthrene<smiles></smiles>

Pyrene<smiles>C1=Cc2c3c(cc4ccccc24)C(=C1)c1ccccc1-3</smiles>

Benzo[b]fluoranthene<smiles>c1cc2cc3c2c2ccc4ccc(c1)c4c3c1ccccc21</smiles>

Indeno[1,2,3-cd]pyrene<smiles>c1cc2c3c(cccc3c1)CC2</smiles>

Acenapthene<smiles>c1ccc2cc3ccccc3cc2c1</smiles>

Anthracene

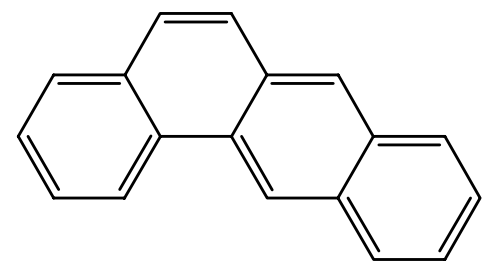

Benzo[a]anthracene

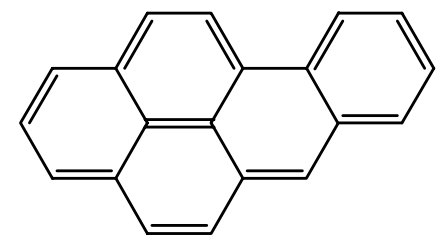

Benzo[a]pyrene

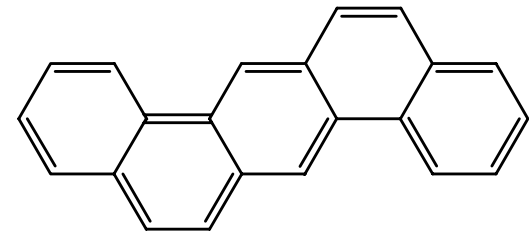

Dibenz[a,h]anthracene 


\section{References}

1. Asphalt Institute:Report to OSHA and NIOSH: Status of Asphalt Industry Steering Committee research program on the health effects of asphalt fumes and recommendation for a worker health standard.(1990)

2. Asphalt Institute:United Sates asphalt usage report.(1989)

3. Jarvholm, B., Nordstrom, G., Levin, J. O., Wahlstrom, J., Ostman, C., and Bergendahl, C.:Exposure to polycyclic aromatic hydrocarbons and genotoxic effects on nonsmoking Swedish road pavement workers.Scand.J.Work Environ.Health25:131-136-(1999)

4. Toraason, M, Hayden, C, Marlow, D., Rinehart, R., Mathias, P., Werren, D., DeBord, D. G., and Reid, T. M.:DNA strand breaks, oxidative damage, and $1-\mathrm{OH}$ pyrene in roofers with coal-tar pitch dust and/or aspahlt fume exposure.Int.Arch.Occup.Environ.Health74:396-404(2001)

5. King, R. W., Puzinauskas, V. P., and Holdsworth, C. E.:Asphalt Composition and health effects: A critical review.Technical Report: American Petroleum Institute:1-11(1984)

6. American Society for Testing and Materials:Terms Relating to Materials for Roads and Pavements, ASTM Designation D8. (1976)

7. R.J.Forbes:Bitumen and Petroleum in Antiquity. (1936) 
8. Process Association:Asphalt Paving Technology. 43A: (1974)

9. U.S.Department of Commerce:Statistical Abstracts of the United States. 716(1961)

10. Gamble, J. F., Nicolich, M. J., Barone, N. J, and Vincent, W. J:Exposure-response of asphalt fumes with changes in pulmonary function and symptoms.Scand.J.Work Environ.Health25:186-206(1999)

11. James Melius:Asphalt - A Continuing Challenge. American Journal of Industrial Medicine43:235-236 (2003)

12. J.G.Speit:The Chemistry and Technology of Petrolium. (1991)

13. J.G.Speit:Fuel Science and Technology Handbook. (1990)

14. National Institute for Occupational Safety and Health:Publication Number 2001110. (2001)

15. National Institute for Occupational Safety and Health:Polynuclear aromatic hydrocarbons: Method 5800. NIOSH Manual of Analytical Methods4th Ed.: (1994)

16. Patra, D. and Mishra, A. K.:Study of diesel fuel contamination by excitation emission maxtrix spectral subtraction fluorescence.

Anal.Chim.Acta.454:209-215 (2002)

17. Guiteras, J, Beltran, J. L., and Ferrer, R.:Quantitative multicomponent analysis of polycyclic aromatic hydrocarbons in water samples. Anal.Chim.Acta.361:233-240 (1998)

18. Alf Bjorseth:Physical and Chemical Properties of PAHs. Handbook of Polycyclic Aromatic Hydrocarbons. 1-25 (1983)

19. Phillips, D. H.:FIfty years of benzo[a]pyrene. Nature303:468-472 (1983)

20. International Agency for Research on Cancer:Monographs on the evaluation of carcinogenic risks to humans. 1:49- (1990)

21. Kathryn Martin Remington, Samuel E.Bennett, and Constance M.Harris:Highly Mutagenic Bypass Synthesis by T7 RNA Polymerase of Site-Specific Benzo[a]pyrene Diol Epoxide-Adducted Template DNA. Journal of Biological Inorganic Chemistry273:13170-13176 (1998)

22. Fang, J. L., Beland, F. A., Doerge, D. R., Wiener, D., Guillemette, C., Marques, M. M., and Lazarus, P.:Characterization of benzo(a)pyrene-trans-7,8dihydrodiol glucuronidation by human tissue microsomes and overexpressed UDP-glucuronosyltransferase enzymes.Cancer Res.62:1978-1986(4-1-2002) 
23. Lee, M, M.V.Novotny, and K.D.Bartle:Analytical chemistry of polycyclic aromatic hydrocarbons. (1981)

24. Nishioka, M., H.-Y.Chang, and M.Lee:Structural characteristics of polycyclic aromatic hydrocarbon isomers in coal tars and combustion products. Environ.Sci.Technol.20:1023-1027 (1986)

25. Wang, Z., M.Fingas, Y. Y. Shu, L.Sigouin, M.Landriault, and P.Lambert:Quantitative characterization of PAHs in burn residue and soot samples and differentiation of pyrogenic PAHs from petrogenic PAHs- the 1994 mobile burn study. Environ.Sci.Technol.33:3100-3109 (1999)

26. The Asphalt Institute:Asphalt Hot-Mix Emmision Study, Research Report RR-75-1. (1975)

27. Gerald Reinke, Mark Swanson, Dennis Paustenbach, and John Beach:Chemical and Mutagenic Properties of Asphalt Fume Condensates Generated Under Laboratory and Field Conditions. Mutation Research/Genetic Toxicology and Environmental Mutagenesis469:41-50 (2000)

28. Watts, R. R., Wallingford, K. M., Williams, R. W., House, D. E., and Lewtas, J.:Airborne exposures to $\mathrm{PAH}$ and $\mathrm{PM}_{2.5}$ particles for road paving workers applying conventional asphalt and crumb rubber modified asphalt.J.Expos.Anal.Environ.Epidemiol.9:213-229(1998)

29. Burstyn, Igor, Kromhout, Hans, Kauppinen, Timo, Heikkila, Pirjo, and Boffetta, Paolo:Statistical Modelling of the Determinants of Historical Exposure to Bitumen and Polycyclic Aromatic Hydrocarbons among Paving Workers. The Annals of Occupational Hygiene44:43-56(2000)

30. Bonnet, P., Binet, S., Brandt, H., Kriech, A. J., Lafontaine, M., Nunge, H., Morele, Y., de Groot, P., Wissel, H., and Castegnaro, M.:Inhalation study on exposure to bitumen fumes: Part 1: Development and validation of the equipment.The Annals of Occupational Hygiene44:15-29(2000)

31. S.Monarca and R.Pasquini, S. G. Scassellati A. Savino F. A. Bauleo G. Angeli:Environmental Monitoring of Mutagenic and Carcinogenic Hazards During Road Paving Operations with Bitumens. Int.Arch.Occup.Environ.Health59:393-402 (1987)

32. Cerniglia, C E.:Biodegredation fo polycyclic aromatic hydrocarbons. Biodegredation3:351-368 (1992)

33. Toxicology and carcinogenesis studies of naphthalene (cas no. 91-20-3) in F344/N rats (inhalation studies).Natl.Toxicol.Program.Tech.Rep.Ser.1-173(2000) 
34. Toxicology and Carcinogenesis Studies of Naphthalene (CAS No. 91-20-3) in B6C3F1 Mice (Inhalation Studies).Natl.Toxicol.Program.Tech.Rep.Ser.410:1-172(1992)

35. Qian, H.-W., Ong, T., and Whong, W.-Z.:Induction of micronuclei in cultured mammalian cells by fume condensates of roofing asphalt.Am.J.Ind.Med.29:554-559(1998)

36. Ma, J. Y., Barger, M. W., Kriech, A. J., and Castranova, V.:Effects of asphalt fume condensate exposure on acute pulmonary responses.Arch.Toxicol.74:452459(2000)

37. Sivak, A., Niemeier, R., Lynch, D., Beltis, K., Simon, S., Salomon, R., Latta, R., Belinky, B., Menzies, K., and Lunsford, A.:Skin carcinogenicity of condensed asphalt roofing fumes and their fractions following dermal application to mice.Cancer Letters117:113-123(7-15-1997)

38. Ma, J. Y., Rengasamy, A., Frazer, D., Barger, M. W., Hubbs, A. F., Battelli, L., Tomblyn, S., Stone, S., and Castranova, V.:Inhalation exposure of rats to asphalt fumes generated at paving temperatures alters pulmonary xenobiotic metabolism pathways without lung injury.Environ.Health Perspect.111:1215-1221(2003)

39. Antonini, J. M., Roberts, J. R., Taylor, M. D., Yin, X., Stone, S., Moseley, A., Ma, J. K., Frazer, D. G., Castranova, V., and Ma, J. Y.:Effect of asphalt fume inhalation exposure at simulated road paving conditions prior to bacterial infection on lung defense responses in rats.Inhal.Toxicol.15:13471368(2003)

40. Fuchs, J., Hengstler, J. G., Boettler, G., and Oesch, F:Primary DNA damage in peripheral mono-nuclear blood cells of workers exposed to bitumen-based products.Int.Arch.Occup.Environ.Health68:141-146(1996)

41. Norseth, T, Waaje, J, and ale, I:Acute effects and exposure to organic compounds in road maintenance workers exposed to asphalt.Am J Ind Med.20:737-744(1991)

42. Maizlish, N, Beaumont, J, and Singleton, J:Mortality among California highway workers.Am J Ind Med.13:363-379(1988)

43. Jiao, Kaisheng and Lafleur, Arthur L.:Improved detection of polycyclic aromatic compounds in complex mixtures by liquid chromatographic fractionation on poly(divinylbenzene) prior to gas chromatography-mass spectrometry: Application to the analysis of diesel particulates.Journal of Chromatography A791:203-211(12-12-1997) 
44. Heikkila, P., Riala, R., Hameila, M., Nykyri, E., and Pfaffli, P.:Occupational exposure to bitumen during road paving.AIHA.J.(Fairfax., Va.)63:156165(2002) 